\title{
Role of reactive oxygen species in tumors based on the 'seed and soil' theory: A complex interaction (Review)
}

\author{
WEI LIANG* ${ }^{*}$ XINYING HE* , JIANQIANG BI, TINGTING HU and YUNCHUAN SUN \\ Department of Radiation Oncology, Hebei Province Cangzhou Hospital of Integrated Traditional and Western Medicine, \\ Affiliated Hospital of Hebei Medical University, Cangzhou, Hebei 061000, P.R. China
}

Received March 23, 2021; Accepted June 24, 2021

DOI: 10.3892/or.2021.8159

\begin{abstract}
Tumor microenvironment (TME) can serve as the 'soil' for the growth and survival of tumor cells and function synergically with tumor cells to mediate tumor progression and therapeutic resistance. Reactive oxygen species (ROS) is somewhat of a double-edged sword for tumors. Accumulating evidence has reported that regulating ROS levels can serve an anti-tumor role in the TME, including the promotion of cancer cell apoptosis, inhibition of angiogenesis, preventing immune escape, manipulating tumor metabolic reorganization and improving drug resistance. In the present review, the potential role of ROS in anti-tumor therapy was summarized, including the possibility of directly or indirectly targeting the TME.
\end{abstract}

\section{Contents}

1. Introduction

2. ROS and TME

3. ROS and tumor drug resistance

4. Conclusions

\section{Introduction}

Reactive oxygen species (ROS) is a general term used to describe molecules with high oxidative reactivity. They are mainly produced by the electron transport chain during

Correspondence to: Professor Yunchuan Sun, Department of Radiation Oncology, Hebei Province Cangzhou Hospital of Integrated Traditional and Western Medicine, Affiliated Hospital of Hebei Medical University, 31 Huanghe West Road, Cangzhou, Hebei 061000, P.R. China

E-mail: sunyunchuan8210@163.com

${ }^{*}$ Contributed equally

Key words: tumor microenvironment, reactive oxygen species, tumor angiogenesis, immune escape, metabolism recombination, tumor drug resistance aerobic respiration in the mitochondria or as a byproduct of the activity of several metabolic enzymes, including xanthine oxidase, lipoxygenase and cytochrome P450 (1). In addition, exogenous stimuli, such as stress, ultraviolet radiation, tumor chemotherapy and radiotherapy (RT), can stimulate ROS production (2). Under physiological conditions, cells can scavenge intracellular ROS using antioxidants, including catalase, glutathione and ascorbic acid, to maintain the dynamic redox balance (3). Once the level of ROS exceed the tolerance threshold of cells, a variety of pathological disorders occur. Previous studies have shown that abnormal ROS levels are closely associated with the occurrence of tumors and neurodegenerative diseases $(4,5)$. During the moderate redox state, ROS can induce tumorigenesis by activating the MAPK and ERK signaling pathway or promoting mutations in the genomic DNA (6). However, previous studies have demonstrated that ROS production is actually inhibited during breast and colon tumor progression, where tumor cells attempt to reduce or eliminate the adverse effects of ROS by potently activating their antioxidant systems $(7,8)$. This leads to resistance to treatments, including chemotherapy, RT and immunotherapy $(9,10)$. In addition, an elevation in ROS levels in breast cancer and human multiple myeloma has been found to promote tumor cell death in different signaling pathways and increase sensitivity to anti-tumor therapy $(11,12)$.

The tumor microenvironment (TME) mainly includes tumor cells and their surrounding immune cells, cancer-associated fibroblasts (CAFs) and vascular endothelial cells (13). It is characterized by hypoxia, low $\mathrm{pH}$, high interstitial pressure, overexpression of glutathione, redox imbalance and immunosuppression $(14,15)$. Paget first proposed the hypothesis of 'seed and soil' in 1989, where tumor cells were known as 'seeds' and the surrounding microenvironment were known as 'soil' (16). Langley and Fidler (17) then revisited this theory and reviewed the close relationship between tumor and angiogenesis in organ metastasis. They found that angiogenesis can promote the metastasis of tumor organs, which provides a theoretical basis for antiangiogenic therapy. Recent studies in stomach and lung cancer have found that in the TME, immune and metabolic reorganization can also promote the occurrence, development, invasion, metastasis of tumors (Fig. 1) $(18,19)$. Manipulating the TME may therefore be more beneficial for controlling the progression of tumors and reverse the drug resistance of tumors. Over the past decade, 
an increasing number of studies have revealed that regulation of the levels of ROS can exert anti-tumor effects by acting on the TME $(20,21)$. These effects include promoting tumor cell apoptosis, inhibiting angiogenesis, inhibiting immune escape, regulating tumor metabolic reorganization and reversing drug resistance $(20,22)$. The present review analyzes the complex role of ROS in anti-tumor therapy in relation to the TME.

\section{ROS and TME}

ROS and tumor cells. Compared with normal cells, cancer cells have a higher level of oxidation $(23,24)$. Excessive ROS renders tumor cells that are already under oxidative stress more fragile, which eventually leads to apoptosis, autophagy and necrosis (Fig. 2).

ROS and apoptosis. Apoptosis is also termed type I programmed cell death and is a form of programmed cell death that serves to clear damaged cells in an orderly manner, which are mainly divided into two types, namely exogenous and endogenous apoptosis (25). The former primarily involves the FasL/FasR, TNF- $\alpha /$ TNF receptor 1 (TNF- $\alpha /$ TNFR1), TNF ligand superfamily member $12 /$ death receptor (DR)3, TNF-related apoptosis-inducing ligand (Apo2L)/DR4, and Apo2L/DR5 signaling pathways (26-29). By contrast, the endogenous signaling pathway is also termed the mitochondrial pathway and mainly entails increasing the permeability of mitochondria, which elevates the concentration of intracellular $\mathrm{Ca}^{2+}$ and regulates the activity of the Bcl-2 family of proteins (30). This effect is accompanied by the release of cytochrome $c$ (Cyt $c$ ), apoptosis-inducing factor and endonuclease $\mathrm{G}$, leading to tumor cell apoptosis $(31,32)$. The final node of apoptosis is mainly initiated by the activation of enzymes in the caspase family $(33,34)$. Under normal conditions, the production and clearance of intracellular ROS are maintained in a dynamic balance. Previous studies have shown that low levels of ROS can promote cell proliferation, whereas excessive accumulation of ROS will lead to colon cancer cell apoptosis $(35,36)$. Tumor cells proliferate at a high rate and are frequently in a state of high oxidative stress (23). Therefore, they tend to be more sensitive to internal and external oxidative stimuli (24). A potential anti-cancer strategy is to aggravate oxidative stress in the cancer cells further by increasing the intracellular ROS levels or by inhibiting the antioxidant capacity of cells $(37,38)$. It has been demonstrated that oxidation of the mitochondrial membrane by ROS can release Cyt $c$ into the cytosol more easily to promote apoptosis (11).

$\mathrm{Bcl}-2$ is a key regulator of apoptosis and as such, ROS levels can influence the functionality of Bcl-2. In a previous study with lung cancer, it was found that excessive ROS production in H460 lung cancer cells inhibit the expression of Bcl-2, whilst increasing the expression $\mathrm{Bcl}-2$ served the effect of inhibiting the increase of ROS (39). In addition, ROS can also regulate a number of exogenous signaling pathways. As the product of the FasL/FasR pathway by the NADPH oxidase system, ROS can activate protein tyrosine kinase, which further promotes Fas-mediated apoptosis (40). A functional relationship between ROS and several signaling pathways has also been found. Zhu et al (41) found that overproduction of ROS in gastric cancer cells can effectively increase the expression of JNK, which then participate in apoptosis mediated by the MAPK pathway. In another study with breast cancer, Zang et al (42) found that ROS can activate the NF- $\kappa \mathrm{B}$ and STAT3 signaling pathways to mediate tumor cell apoptosis. Many chemotherapeutic drugs function by increasing the production of ROS, which leads to irreversible apoptosis. Sulindac is a nonsteroidal anti-inflammatory drug. In the treatment of lung cancer, it has been shown to increase ROS production and subsequent mitochondrial membrane damage, which promoted tumor cell apoptosis (43). Doxorubicin can also increase the production of ROS and activate the tumor suppressor p53, resulting in tumor cell death (44). In addition, photodynamic therapy, RT and emerging sonodynamic therapy, chemodynamic therapy, enzyme dynamic therapy and ROS-based nanomedicine therapy have all been documented to serve anti-tumor roles by increasing the levels of cellular $\operatorname{ROS}(22,45,46)$.

ROS and autophagy. Autophagy is termed type II programmed cell death and is a process in which cells remove intracellular damage, senescent organelles and structural and biological macromolecules, such as proteins and lipids, by lysosome-mediated degradation (47). Autophagy is highly conserved and is regulated by the autophagy-related (ATG) family of proteins (47). It is now considered to be not only a mechanism of cell survival, but also an inhibitory mechanism that can induce the death of transformed cancer cells (47). ROS is a classical autophagy inducer and a key component for the interaction between apoptosis and autophagy (48). In general, autophagy induced by moderate levels of ROS can reduce the damage caused by oxidative stress and protect cells (49). By contrast, high levels of ROS can activate autophagic cell death and have destructive effects on cells (49). Wu et al (50) previously showed that $\mathrm{H}_{2} \mathrm{O}_{2}$ pretreatment triggered autophagy in hepatocellular carcinoma (HCC) cells, where high concentration of $\mathrm{H}_{2} \mathrm{O}_{2}$ could stimulate autophagic apoptosis in HCC cell lines. Another study has also shown that excessive ROS may induce autophagic cell death in human oral cancer CAL 27 cells by promoting Unc51-like kinase 1 protein ubiquitination and upregulating the expression of the autophagy-related protein Beclin-1 (51). In addition, ROS can also alter the activity of signaling pathways that regulate autophagy. Activation of mTOR kinase, an enzyme in the autophagic pathway, is inhibited by the AKT and MAPK signaling pathways (52). AKT induces protective autophagy whilst sustaining the degradation of p53 and the expression of $\mathrm{NF}-\kappa \mathrm{B}$ in HCC cells (53). Therefore, pathways that negatively regulate $\mathrm{mTOR}$, including the protein kinase 5'AMP-activated protein kinase and p53, which are sensitive to oxidative stress, can promote autophagy $(53,54)$.

ROS and necroptosis. Cell necrosis is currently considered to be a type III programmed cell death (55). It is initiated by TNFR1 and transmits cell death signals through receptor-interacting serine-threonine kinase 1 (RIP1). RIP3 and mixed lineage kinase domain-like pseudokinase (MLKL) (55). It has been previously reported that ROS can promote the autophosphorylation of Serine 161 on RIP1 $(56,57)$. Phosphorylated RIP1 can then recruit RIP3 to form the programmed necrosis complex, which activate programmed necrosis to increase 


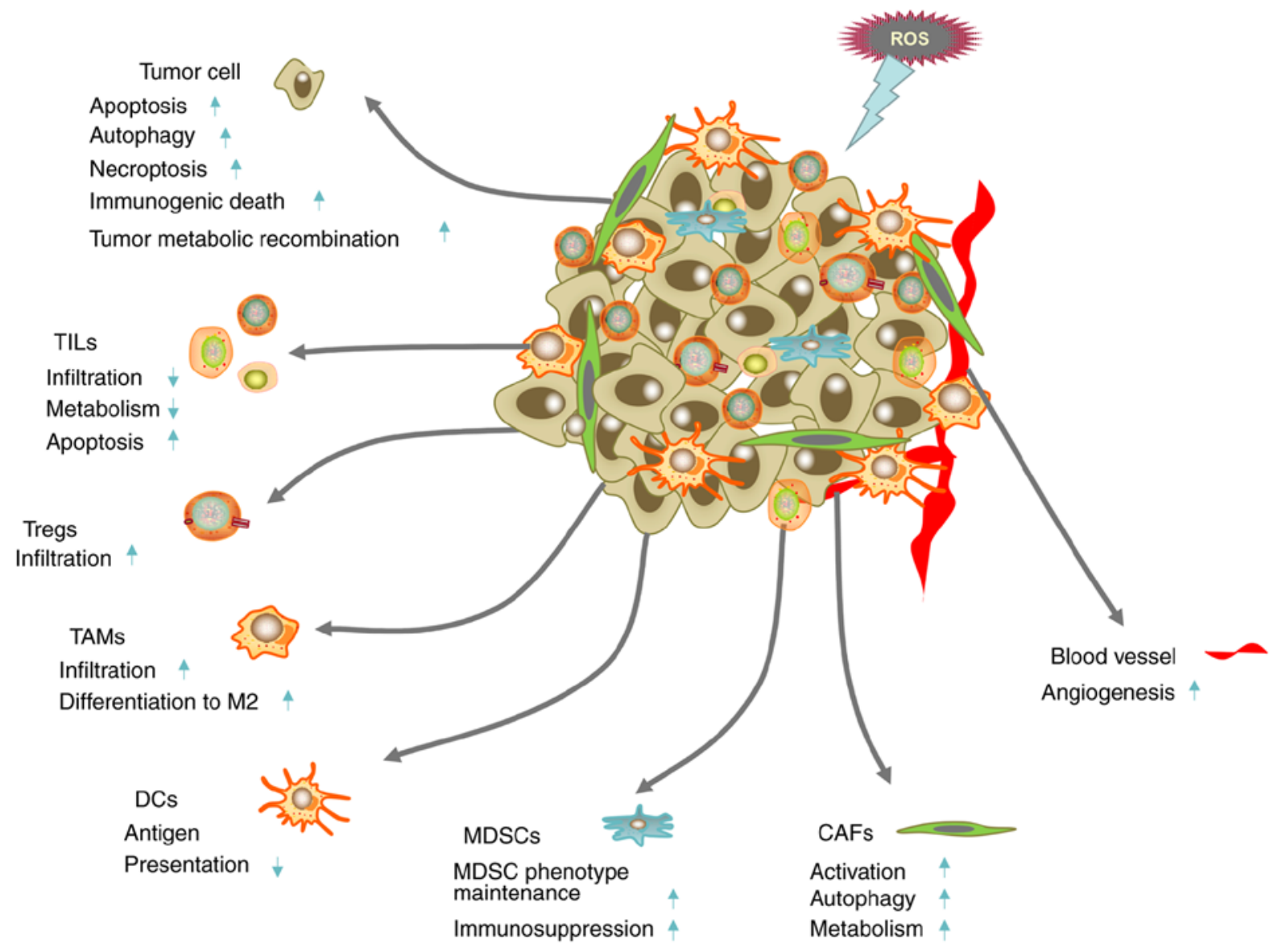

Figure 1. Complexity of the interaction between ROS and the TME. The up and down arrows represent cell responses to ROS treatment. ROS can promote tumor cell death, promote tumor metabolic reprogramming, induce tumor angiogenesis and activate CAFs and autophagy. ROS can also reduce lymphocyte infiltration, reduce the antigen presenting ability of DCs and maintain the immunosuppressive function of Treg cells and MDSCs to promote the formation of the immunosuppressive microenvironment. CAF, cancer-associated fibroblast; DC, dendritic cell; MDSC, myelogenic suppressor cell; ROS, reactive oxygen species; TAM, tumor-associated macrophage; TIL, tumor-infiltrating lymphocyte; TME, tumor microenvironment; Treg, T regulatory cells.

the intracellular ROS content further, completing the positive feedback loop (58). A previous study with melanoma have found that increasing ROS can regulate RIP1 to promote melanoma cell necrosis, where the JNK signaling pathway was involved (59). Yang et al (60) demonstrated that RIP3 can phosphorylate the pyruvate dehydrogenase complex to promote cell oxygen consumption and ROS production in murine fibroblast L929 cells, which enhanced the formation of necrotic bodies following stimulation by TNF. Additionally, p53 has also been implicated in ROS-induced programmed necrosis. Tu et al (61) showed that etoposide can induce the necrosis of fibroblasts in a BAX/BAK double-knockout mouse embryonic model. This was found to be the result of a synergistic interaction between DNA damage-induced ROS and p53-induced elevation of cathepsin Q (61). In a study of mouse embryonic fibroblasts, during oxidative stress, p53 has been reported to accumulate in the mitochondrial matrix and interact with the cyclophilin D regulator located in the intima of the mitochondrial permeability transition pore (62). This resulted in mitochondrial damage, ROS production and finally programmed cell necrosis (62).

ROS and angiogenesis. Serving as the 'soil' for the growth of cancer cells, the TME must provide sufficient nutrition for them. Neovascularization is the main method used for the transport of nutrients during tumor occurrence and metastasis (63). It has been shown that ROS can regulate tumor angiogenesis and promote angiogenesis by targeting transcription factors or tumor suppressors, such as activating protein 1, hypoxia inducible factor- $1 \alpha$ (HIF-1 $\alpha), \mathrm{NF}-\kappa \mathrm{B}$, and p53 (64). However, in recent years, it has been found that the increase of ROS production in the TME can reduce neovascularization and inhibit tumor progression (65). Inducing apoptosis in vascular endothelial cells is generally considered to be the core strategy for inhibiting angiogenesis and treating related diseases, including cancer, neovascular age-related macular degeneration and diabetic retinopathy (66). ROS is a promoter of vascular and endothelial cell death in colon and breast tumors $(67,68)$. Owing to the atypical metabolic environment, vascular endothelial cells in the TME generally exhibit higher levels of ROS compared with those in normal vascular endothelial cells and are more vulnerable to cytotoxicity caused by a further increment in ROS levels (69). Therefore, increasing the ROS levels further is more likely to aggravate cell death (69). Topalovski et al (70) found that fibulin-5 can promote ROS production in vascular endothelial cells by acting on the fibronectin receptor $\beta 1$ to exert its anti-angiogenic effects in pancreatic cancer cells. In addition, N-benzyl-2-nitro-1-imidazole-acetamide, a therapeutic agent for Chagas disease, has been found to exert anti-tumor effects 


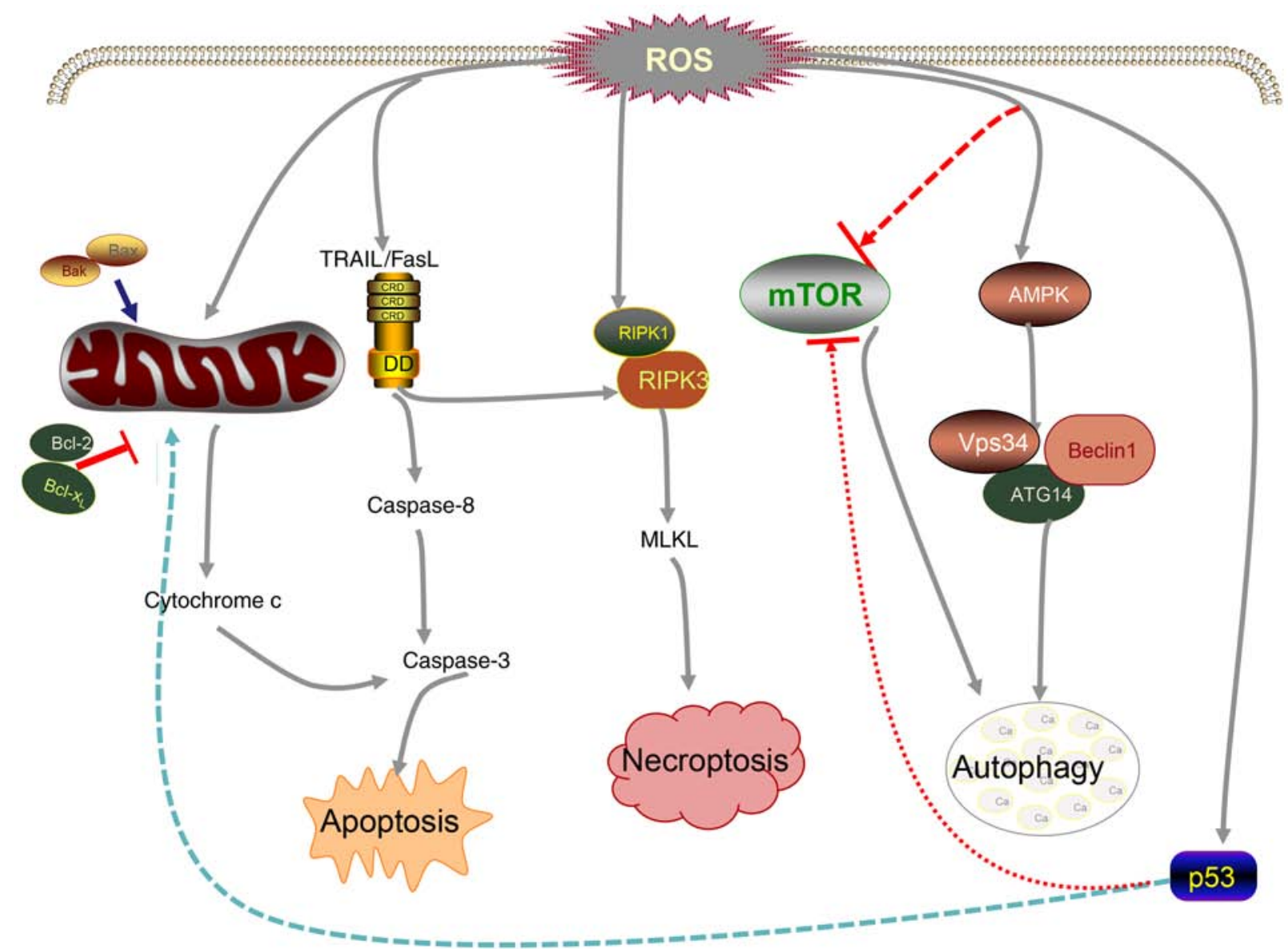

Figure 2. Mechanism of cancer cell death induced by ROS. Elevated ROS can reduce Bcl-2 activity, promote the release of cytochrome $c$ and activate death-related ligands TRAIL/FasL, thereby promoting caspase-mediated apoptosis. High levels of ROS can also promote the formation of the RIPK-1/RIPK-3 complex and eventually lead to necrosis. Moreover, ROS can inhibit the activity of mTOR, promote the activation of AMPK and subsequently induce autophagy. p53 is involved in ROS-mediated cancer cell death. ATG14, autophagy related 14; 5'AMPK, AMP-activated protein kinase; FasL, Fas ligand; MLKL, mixed lineage kinase domain-like pseudokinase; RIPK, receptor interacting serine/threonine kinase; ROS, reactive oxygen species; TRAIL, TNF-related apoptosis-inducing ligand; Vps34, vacuolar protein sorting 34 .

in Ehrlich tumor cells by increasing ROS levels and inhibiting angiogenesis (71). Synthesis of redox regulators using silver nanoframe technology has been shown to induce excessive ROS generation and enhance cytotoxicity in the vascular endothelium (72). This prevented formation of the tubular network in the endothelial cells and poly-ADP ribose modification of VEGF, thereby inhibiting angiogenesis (72). Furthermore, Cao et al (73) found that decylubiquinone can increase ROS to inhibit the formation of the tubular structure through the ROS/p53/brain-specific angiogenesis inhibitor 1 signaling pathway in the chicken embryo chorioallantoic membrane model.

ROS and CAFs. CAFs are particularly abundant in the matrix and can be derived from a variety of sources (74). They serve an important role in tumor growth, metastasis and drug resistance $(74,75)$, by secreting a variety of cytokines and growth factors. The specific mechanisms involved in these effects include the maintenance of cancer stem cell (CSC) stemness, promotion of epithelial-mesenchymal transformation (EMT), remodeling of the vascular system and regulation of tumor immunity (76-79). In previous years, it was found that the autophagy of CAFs can also serve an important role in the occurrence and development of tumors $(80,81)$. Activation of
CAFs is largely dependent on the stimulation of TME by local hypoxia, oxidative stress, growth factors released by adjacent tumor cells and infiltrating immune cells (82). A previous study with ovarian cancer has shown that ROS produced by tumors can induce the expression of chloride intracellular channel 4, chemokine (C-C motif) ligand $2, \mathrm{TGF}-\beta 1, \mathrm{NF}-\kappa \mathrm{B}$ and STAT3 in CAFs to induce their activation (83). In addition, ROS can also induce myofibroblast differentiation by upregulating the expression of chemokine (C-X-C motif) ligand-12 whilst downregulating that of caveolin 1 (CAV1) (84-86). ROS can also play an important role in the regulation of CAF autophagy. Tumor cells have been observed to induce oxidative stress in adjacent CAFs (87). In breast cancer, an increase in the levels of ROS can activate the expression of HIF-1 $\alpha$ and NF- $\mathrm{NB}$ in CAFs to subsequently induce CAF autophagy, which may lead to a decrease in ROS-dependent CAV1 expression (88). The downregulation of CAV1 promotes mitochondrial dysfunction and oxidative stress further in CAFs, thereby forming a positive feedback loop $(88,89)$. In addition, ROS can also regulate the metabolism of CAFs. In tumor cells, even under aerobic conditions, glycolysis is highly active, which is characterized by increased glucose uptake and increased lactic acid secretion (90). This is known as the 'Warburg effect' (90). CAFs will also produce a similar phenomenon of aerobic 
glycolysis under the influence of tumor cells, which is called the 'reverse Warburg effect' (86). During this phenomenon, oxidative phosphorylation of tumor cells produces a large quantity of ROS, which specifically triggers oxidative stress in CAFs and disrupts the oxidative phosphorylation system (86). This results in the additive accumulation of ROS and induces a chain reaction of oxidative stress (86). The mode of glucose metabolism in CAFs changes from oxidative phosphorylation to glycolysis, which produces high-energy raw materials, such as lactic acid and ketone, which supply tumors to promote cell division and support Kreb's cycle (86). Additionally, an acidic microenvironment with high lactate content is also created during this event, which inhibits the growth of normal cells whilst promoting tumor cell proliferation and metastasis (86). Inhibition of CAV1 by ROS is known to be one of the driving factors for changing in the metabolic pattern of CAFs (91). Martinez-Outschoorn et al (92) previously found that when the MCF7 breast cancer cells were co-cultured with fibroblasts, tumor cell apoptosis occurred after the removal of $\mathrm{H}_{2} \mathrm{O}_{2}$. This effect was proposed to be caused by the lack of lactic acid produced by CAFs in tumor cells (92).

ROS and the immune microenvironment. In recent years, tumor immunotherapy, including immune checkpoint inhibitors (93), chimeric antigen receptor-T cell therapy and tumor vaccines (94), has emerged as another promising anti-cancer therapeutic strategy after surgery, chemotherapy and RT. Although clear therapeutic effects have been achieved, in current clinical practice immunotherapy can only offer lasting survival benefits to $20-30 \%$ of the patients, since most patients will face the problems of insensitivity or resistance to immunotherapy (95). For example, ipilimumab, a cytotoxic T-cell lymphocyte antigen-4 inhibitor, has a positive response rate of only $15 \%$ in patients with advanced melanoma (96). Similarly, the positive response rate of drugs that target programmed cell death 1/programmed cell death ligand 1 (PD-1/PD-L1) signaling rarely exceeds 40\% (97). Previous studies have found that limited $\mathrm{T}$ lymphocyte infiltration or low immunogenicity of the TME is the main reason for the failure of treatment $(98,99)$. The interaction between tumor cells and immune cells is a core feature of the TME $(100,101)$. Owing to the high plasticity of immune cells, tumor cells promote the maturation, differentiation and recruitment of immunosuppressive cells by secreting IL-10, TGF- $\beta$, and VEGF to construct an immunosuppressive TME $(102,103)$. In turn, the immunosuppressive cells can promote tumor growth, metastasis and escape from immune surveillance (103). ROS was found to be an effector of cytotoxicity induced by numerous anti-cancer drugs, which is a byproduct of cellular oxidative metabolism (104). As signal mediators, ROS serves a key role in the immune monitoring of regulatory (Tregs) and effector T cells, which relies on classical receptors, such as toll-like receptors, and perception of the metabolic environment $(104,105)$. The concentration of ROS in tumor tissues is typically higher compared with that recorded in surrounding normal tissues (23). In the TME with persistently high ROS levels, both immune and tumor cells are affected. The increase of ROS is one of the main causes of immunosuppression in the TME (106). However, some studies have shown that increasing ROS levels can induce immunogenic death (ICD) in tumor cells $(107,108)$, which exhibits a synergistic effect with immunotherapy (107). A growing body of evidence suggests that targeting the redox levels of immune cells can result in a variety of phenotypes and functions, which can overcome immunosuppression in the TME to ultimately inhibit tumor growth $(21,22)$. In this section, the function and effect of ROS on the different tumor-infiltrating immune cell types were explored, with focus on the effect of ROS in tumor immunotherapy (Fig. 1).

ROS and lymphocytes. T cells (also known as T lymphocytes) consist of a heterogeneous group of lymphocytes in the tumor matrix, which includes cytotoxic $\mathrm{T}$ lymphocytes, helper T lymphocytes and Tregs (109). They mediate immune surveillance and the killing of cancer cells (109). ROS participate in the regulation of $\mathrm{T}$ cells in the TME. Murphy and Siegel (110) previously reported that following reduction in mitochondrial ROS produced by complex III, $\mathrm{T}$ cells could no longer be continuously activated even after stimulation by CD3 or CD28. Activation of T cells requires stimulation of the T-cell receptor (TCR) through the induction of the MAPK signal transduction pathway and transcription factors such as nuclear factor of activated T cells (NFAT), $\mathrm{NF}-\kappa \mathrm{B}$ and activator protein-1 (111). Studies $(112,113)$ have shown that mitochondrial ROS can be transferred to $\mathrm{T}$ cell immune synapses. After stimulation by antigens, $\mathrm{H}_{2} \mathrm{O}_{2}$ in the mitochondria can enhance the MAPK signaling pathway, leading to $\mathrm{T}$ cell activation and proliferation (112). However, a number studies have also shown that high levels of ROS in the TME can inhibit the activation, proliferation and anti-tumor function of T cells (114-117). $\mathrm{H}_{2} \mathrm{O}_{2}$-mediated activation of TCR can promote the production of mitochondrial superoxides, which can enhance the expression of FasL in $\mathrm{T}$ cells and contribute to $\mathrm{T}$ cell activation-induced cell death $(114,115)$. Recent studies have shown that chronic oxidative stress can cause T cell weakness or failure $(116,117)$.

PD-1 is an immunosuppressive receptor that is mainly expressed in activated $\mathrm{T}$ cells and can exert negative immunoregulatory effects after activation by the PD-L1 ligand on the surfaces of antigen-presenting cells (118). Kumar et al (119) and Chamoto et al (120) previously found that ROS and mitochondrial activation serve an important role in $\mathrm{T}$ cell immunity induced by PD-1 blockade. PD-1 blocking treatment can increase the ROS content in $\mathrm{T}$ cells (119). Using a 'bilateral tumor model', it was found that boosting mitochondrial activity of $\mathrm{T}$ cells by the addition of bezafibrate, a pan-peroxisome proliferator-activated receptor agonist, can partially improve the efficacy of PD-1 blockade in a lung cancer model with systemic immunosuppressive properties (119). These findings suggest that regulation of mitochondria-derived ROS in T cells may have an impact on PD-1 blocking therapy. Another study (121) found that use of the phenothiazine calmodulin inhibitor trifluoperazine could increase the levels of ROS and stimulate the expression of PD-L1 in colorectal cancer cells, tumor-infiltrating $\mathrm{CD}^{+}$and $\mathrm{CD}^{+} \mathrm{T}$ cells. However, other studies have shown that enhanced ROS levels in neck squamous carcinoma cells can also reduce the expression of PD-L1 $(122,123)$. Therefore, ROS can exert different biological effects in a manner that is dependent on its quantity, where different levels of ROS can mediate different immune cell responses. 
Treg cells belong to a typical class of immunosuppressive cells. In particular, the $\mathrm{CD}^{+}{ }^{+}$subset of forkhead box P3 (FOXP3) Tregs can play an important role in mediating tumor immune tolerance (124). It has been shown that the levels of ROS in the microenvironment are associated with immune tolerance mediated by Treg cells (125). By contrast, ROS can promote the differentiation of Treg cells (126). It was found that bile acid can promote the differentiation of Treg cells by increasing the levels of mitochondrial ROS, which subsequently increased the acetylation of H3K27 in the Foxp3 promoter (126). Kunisada et al (127) demonstrated that metformin blocked the differentiation of immature $\mathrm{CD}^{+} \mathrm{T}$ cells into Treg cells by inhibiting mitochondrial ROS, which subsequently downregulated the expression of FOXP3 and reduced the number of tumor-infiltrating Treg cells. Conversely, ROS can also maintain the function of Treg cells. Yu et al (128) found that ROS induced by TCR signaling specifically inhibited the protein degradation of deubiquitin-like enzyme SUMO-specific peptidase 3 (SENP3), which preserved the immunosuppressive activity of Treg cells. Interfering with the levels of ROS can specifically inhibit the expression of SENP3, resulting in the weakening of Treg cell function and consequently improve the tumor immune response. Maj et al (129) revealed the relationship between ROS and immunosuppression by Treg cells in the TME of ovarian cancer. The results of this previous study showed that ROS in the TME may cause the apoptosis of Treg cells, where the apoptotic cells can subsequently release large quantities of adenosine triphosphate (ATP) (129). Although ATP is beneficial to body function under normal circumstances, early apoptotic Treg cells can rapidly convert ATP to adenosine by CD39 and CD73 (129). These adenosines are specific to T cells and can bind to their cell surface adenosine A2A receptors to inhibit T cell activation (129). In conclusion, ROS can serve an important role in the function of $\mathrm{T}$ cells, whereby high levels of ROS in T cells may confer anti-tumor effects, whereas ROS in Treg cells appear to be associated with immunosuppression.

ROS and natural killer (NK) cells. NK cells are a type of effector lymphocytes that play an important role in the anti-tumor process and are profoundly influenced by hypoxia and oxidative stress in the TME (130). Zheng et al (131) previously found that hypoxia in the TME led to an increase in the levels of ROS, which could continuously activate the mTOR/dynamin-related protein 1 pathway in $\mathrm{NK}$ cells, resulting in excessive mitochondrial fission. After mitochondrial fragmentation, the production of ROS was accelerated and a positive feedback loop was established (131). This process ultimately leaded to apoptosis and mitochondrial autophagy, which decreased the activity and tumor killing ability of NK cells (131). Therefore, the aberrant increase in ROS levels in the TME may be one of the mechanisms underlying the failure of NKs. Supporting this, reducing ROS levels in the TME or improving the tolerance of NK cells to ROS have been reported to prevent this failure (132-134).

\section{ROS and antigen-presenting cells (APC)}

ROS and dendritic cells (DCs). DCs are professional antigen-presenting cells that play an important role in both innate and adaptive immunity. Immature DCs have strong migratory ability, whilst mature DCs can effectively activate initial $\mathrm{T}$ cells to initiate, regulate and maintain the immune response (135). The relationship between ROS and DCs is complex, which involve both metabolic and transcriptional changes (136). Previous studies have found that an increase in the environmental redox potential can hinder cross presentation $(137,138)$. Excessive ROS can lead to the chronic activation of the endoplasmic reticulum stress response and oxidative damage to intracellular lipids, which inhibit the ability of DCs to present local antigens to T cells $(137,138)$. These effects aforementioned can impede the development of an effective anti-tumor immune response. However, low levels of ROS can act as a key signaling component to promote the maturation of antigen-presenting cells through the activation of signaling pathways, including NF- $\mathrm{B}$, mTOR and ERK, in addition to the activation of intracellular $\mathrm{Ca}^{2+}$ channels (139). It has been demonstrated that ROS can promote cytoplasmic antigen transmission in DCs by lysosome escape and antigen protection, resulting in effective antigen cross presentation and strong $\mathrm{CD}^{+} \mathrm{T}$ cell responses $(140,141)$.

ROS and macrophages. Macrophages are mainly derived from myeloprogenitor cells in the bone marrow and serve the innate immune system (142). Tumor-associated macrophages (TAMs) have been frequently observed to infiltrate the tumor tissue, which serve an 'accomplice' role in tumor development and metastasis(142). They can bedivided into the $\mathrm{M}_{1}$ and $\mathrm{M}_{2}$ subtypes, which are thought to inhibit and promote cancer progression, respectively (142). Reprogramming or repolarization of TAMs to an anti-tumor phenotype may be an effective method for enhancing the efficacy of immunotherapy (143). Previous studies have shown that continuously increasing the levels of ROS in the TME can contribute to the differentiation of TAMs into the $\mathrm{M}_{2}$ subtype $(144,145)$. TAMs that were isolated from melanoma after high ROS treatment appeared to show a more aggressive phenotype, which may be associated with the secretion of ROS-dependent TNF- $\alpha$ in mouse melanoma B16F1 and B16F10 cell lines (146). Griess et al (147) found that ROS elimination can selectively inhibit the polarization and tumor-promoting function of $\mathrm{M}_{2}$ macrophages through the STAT3 signaling pathway. In addition, it was found that $\mathrm{M}_{2}$ TAMs can express PD-1, but ROS clearance can polarize the TAM balance towards the $\mathrm{M}_{1}$ phenotype and reduced the expression of PD-L1 (148). However, the effects of ROS on TAM differentiation and regulation of the PD-1 immune checkpoint pathway are worthy of further study.

ROS and B cells. B cells are derived from bone marrow and are specialized antigen-presenting cells that can also mediate the humoral immune response by producing antibodies (149). A number of previous studies found a positive correlation between $\mathrm{B}$ lymphocyte infiltration and patient response to immunotherapy in various types of tumors, such as sarcoma, melanoma and renal cell carcinoma, which highlights the important role of B cells in anti-tumor immunity (150-152). A study has also found that increasing ROS levels in the microenvironment can promote the expression of $\mathrm{HIF}-1 \alpha$, nuclear factor erythroid 2-related factor 2 (NRF2) and C-X-C chemokine receptor type 4 , which in turn regulate the multiple stages of B cell development (153). Feng et al (154) previously 
found that $\mathrm{B}$-cell receptor (BCR)-induced $\mathrm{B}$ cell activation also required ROS (154), similar to T cells. Mechanistically, ROS mediates the activation and proliferation of $\mathrm{B}$ cells by activating the NF- $\kappa \mathrm{B}$ and PI3K signaling pathways (154). After treatment with $\mathrm{N}$-acetylcysteine for $3 \mathrm{~h}$, the proliferation of B cells was significantly inhibited (154). ROS has also been found to determine cell fate after B-cell activation. B cells treated with high levels of ROS can undergo class switch recombination, whereas low levels of ROS can induce differentiation into plasma cells (155). In addition, ROS can regulate apoptosis and autophagy in B cells $(156,157)$. The p66SHC protein not only antagonized BCR survival signals and promoted apoptosis, but also prevented B cell survival through selective autophagy/mitochondrial autophagy, by increasing ROS production $(156,157)$. In conclusion, ROS can be considered to be involved in multiple stages of $\mathrm{B}$ cell development, including activation, differentiation and death.

ROS and myeloid-derived suppressor cells (MDSCs). MDSCs are heterogeneous cell groups that consist of myeloid progenitor cells and immature bone marrow cells (IMCs). They form an important part of the TME and possess potent immunosuppressive activity (158). ROS serve an important role in maintaining the undifferentiated state of MDSCs (159). In mice transplanted with colon cancer and sarcoma, scavenging of $\mathrm{H}_{2} \mathrm{O}_{2}$ induced the differentiation of immature myelocytes into macrophages (160). Of note, in the absence of NADPH oxidase (NOX) activity, MDSCs differentiated into macrophages and DCs (160). Therefore, endogenous oxidative stress may be a mechanism of MDSC inhibition to suppress its differentiation in tumors. MDSCs can act on other immune cells through ROS. It has been previously found that ROS produced by MDSCs can permanently inactivate T cells and destroy their ability to initiate the immune response (161). Inhibition of ROS in MDSCs can reverse immunosuppression and exert anti-tumor effects (161). In addition, not only the $\mathrm{T}$ cell response is a target of ROS-mediated MDSC inhibition. MDSCs can also inhibit the response of NK cells to adenovirus vectors and vaccinia virus infection by releasing ROS $(162,163)$. Recent studies have shown that MDSCs can also negatively regulate $\mathrm{B}$ cell-mediated immune response through ROS $(164,165)$. Lelis et al (166) found that MDSCs can inhibit $\mathrm{B}$ cell proliferation and antibody production by cell contact through argininase, nitric oxide and ROS. In addition to playing a role in MDSC-mediated immunosuppression, ROS has also been found to be intrinsically involved with the activation of transcription factors, including NRF2 and HIF-1 $\alpha$ (167). This process induces the transcriptional and metabolic reprogramming of MDSCs, which affects their differentiation and maintenance (167). Therefore, in the TME, ROS act as inducers of oxidative stress and a medium of immune regulation, which is an important process in the formation of cancer cells (159).

ROS and ICD. Tumors maintain the microenvironment of immune suppression by displaying low immunogenicity and secreting immunosuppressive cytokines, including IL-10, TGF- $\beta$, and VEGF (168). ICD can be triggered by various treatments, such as chemotherapy, RT and photodynamic therapy (169). Various cell death-related molecules, such as damage-associated molecular patterns, are released to enhance the immunogenicity of tumor cells and the initial immune response, which is an innovative measure in immunotherapy (169). At present, the prevailing notion is that there is a positive association between ROS production and ICD induction in anti-tumor therapy (170). Excessive levels of ROS are frequently used for the oxidative killing of tumors and induction of ICD. These processes can provide potential antigen stimulation to the immune system. A nano-study based on sonodynamic therapy found that enhanced continuous ultrasonic-triggered inertial cavitation increased ROS production and induced strong ICD (107). This was characterized by increased antigen exposure and presentation, enhanced maturation of DCs and increased infiltration of active-effector $\mathrm{CD}^{+} \mathrm{T}$ cells (107). Li et al (171) previously explored the potential use of a fluorine-assembled nanocluster to reverse immunosuppression and reawaken the immune system. Following the production of sufficient ROS levels by fluorine assembly ${ }^{\circledR}$ photodynamic immunotherapy for tumor (PMPt) to break ROS-sensitive connectors under laser irradiation, cisplatin-coupled PMPt is released to penetrate the tumor and kill Treg cells and MDSCs (171). Additionally, ROS can strongly induce ICD by increasing infiltration by DCs and T cells to turn a cold tumor into a hot tumor and stimulate an effective anti-tumor immune response (171). However, a number of studies have shown that the increase of ROS in the TME can markedly reduce ICD and the number of tumor-infiltrating $\mathrm{T}$ lymphocytes $(172,173)$. In a previous study using a breast cancer model, Deng et al (172) found that the elimination of ROS from the TME using nano-scavengers could alleviate immunosuppressive ICD induced by oleandrin anticancer drug and prolong the survival time of $\mathrm{T}$ cells in breast cancer. Elimination of ROS also lead to an increase in anti-tumor immunity and $\mathrm{T}$ lymphocyte infiltration, resulting in a potent anti-tumor effect (172). It is hypothesized that these contradictory results may be related to the different levels of ROS. Therefore, further studies are warranted to confirm these findings aforementioned.

ROS and tumor metabolic recombination. Glucose deficiency is a characteristic of the TME (174). For the maintenance of survival and rapid proliferation, tumor cells will undergo a series of metabolic reprogramming to improve their adaptability to nutritional deficiency, particularly to glucose (174). Metabolic reprogramming of tumor cells frequently leads to the excessive production of ROS and oxidative stress, but tumor cells can maintain ROS homeostasis and prevent ROS-mediated cell death by enhancing their antioxidant system (175). Low concentrations of ROS can promote tumor metabolism by altering the activity of key enzymes, including pyruvate kinase M2, GAPDH and $\alpha$-ketoglutarate, inducing metabolism-related genomic changes and activating a number of signaling pathways (Fig. 3) (176). It has been found that overlapping with the m-AAA protease 1 homolog can promote the production of ROS, improve the stability of HIF-1 $\alpha$, and increase the expression of glucose transporters and glycolytic enzymes, including hexokinase 2 and lactate dehydrogenase (LDH) A, under hypoxic conditions (177). These effects lead to an increase in the glycolytic ability of colorectal cancer cells (177). To investigate the role of the non-classical 


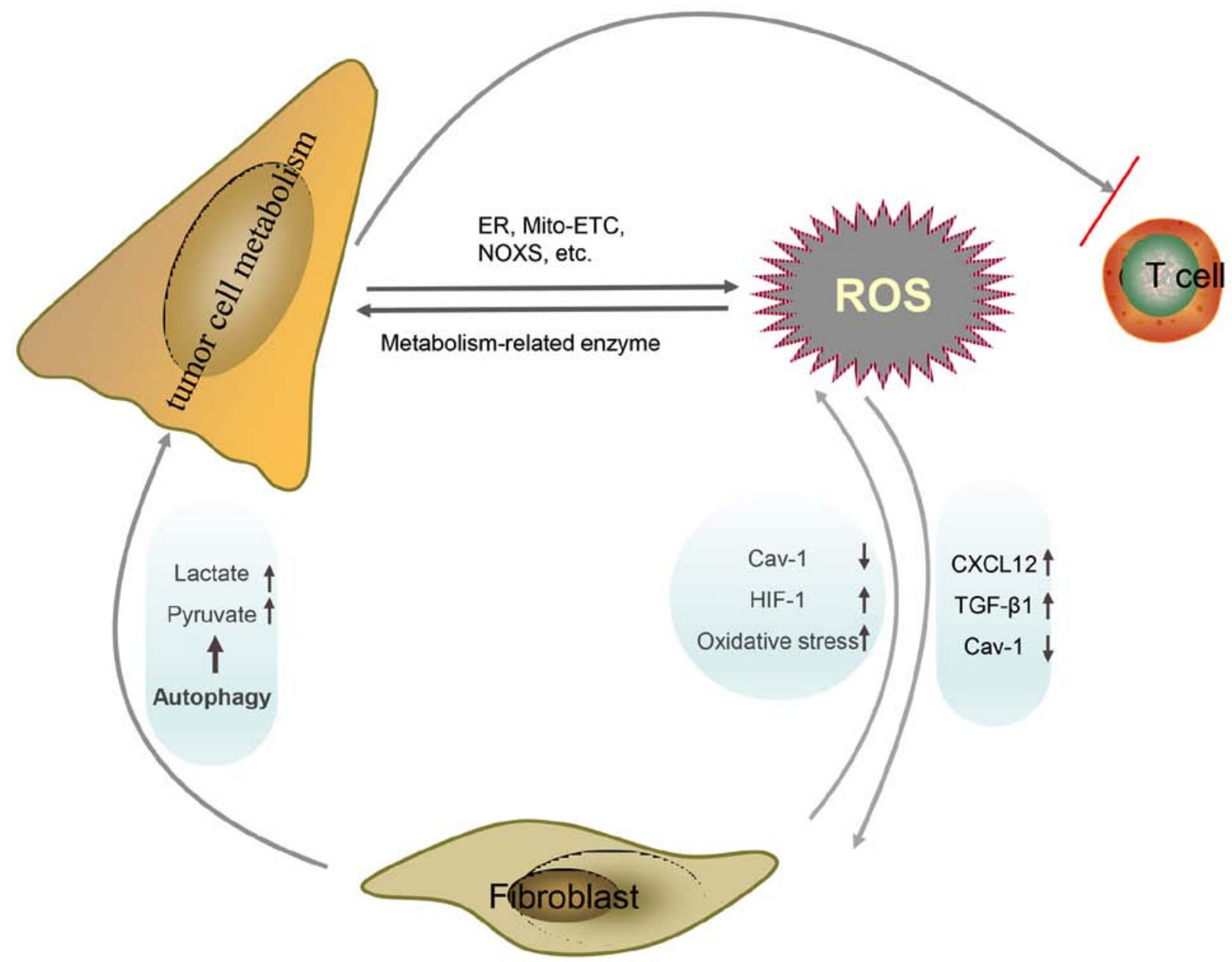

Figure 3. Regulation of ROS in tumor cell metabolism. Specifically, metabolic alterations in cancer cells cause the accumulation of ROS, which in turn acts on metabolic enzymes to promote the metabolic programming of cancer cells. The accumulation of ROS can also activate CAFs and promote autophagy, which can further increase the accumulation of ROS and provide raw materials for tumor metabolism. In addition, ROS are also involved in the inhibition of T cell function by tumor metabolism. CAFs, carcinoma associated fibroblasts; Cav-1, caveolin-1; CXCL12, chemokine (C-X-C motif) ligand 12; ER, endoplasmic reticulum; HIF-1, hypoxia inducible factor 1; Mito-ETC, mitochondrial electron transport chain; NOXS, NADPH oxidases; ROS, reactive oxygen species.

glutamine pathway in the development of pancreatic cancer, Wang et al (178) found an imbalance in ROS in the occurrence and development of the disease. ROS inhibited arginine methylation enzyme coactivator associated arginine methyltransferase 1 , which in turn inhibited the activity of malate dehydrogenase malate dehydrogenase 1 . These observations suggest that ROS activated the non-classical glutamine metabolism to promote the growth of pancreatic cancer cells. ROS can also promote tumor metabolic reprogramming by activating NRF2, which increases the expression of NADPH-generating enzymes, such as glucose-6-phosphate dehydrogenase, isocitrate dehydrogenase 1 and malic enzyme 1 (ME1), and supports lung cancer growth by increasing NADPH and purine biosynthesis (179). In addition, ROS can also mediate the metabolic interaction between tumor cells and their microenvironment. As aforementioned, tumor cells can produce a large quantity of ROS through metabolism (86). This triggers the 'reverse Warburg effect' in CAFs to produce lactic acid, ketone and other high-energy raw materials to improve the metabolic plasticity of tumor (86). ROS can also reduce the expression of CAV1 and promote the transformation of myofibroblasts (87). In pancreatic, breast, lung and prostate cancer, it has been demonstrated that downregulation of CAV1 expression is associated with the overexpression of key metabolic enzymes, including pyruvate kinase isozymes M2 and LDH (180-182). In addition, the transport of lactic acid and ketone bodies, which are glycolytic products, can also be detected at the same time of CAV-1 downregulation (180-182). ROS can also mediate the interaction between tumor metabolism and the immune microenvironment. In a previous study with ovarian cancer (183), it was found that tumors can mediate effector $\mathrm{T}$ cell dysfunction by inhibiting the expression of the histone-lysine N-transmethylase 2 enhancer of zeste homolog 2 by glucose restriction. $T$ cells isolated from malignant ascites in patients with ovarian cancer were found to activate the inositol requiring kinase $1 \alpha$-X-box binding protein-1 endoplasmic reticulum stress response, which reduced glucose uptake and inhibited mitochondrial activity (184). This finding suggests that oxidative stress and glucose deprivation in the TME may contribute to lymphocyte dysfunction in human tumors.

\section{ROS and tumor drug resistance}

The prognosis of cancer has markedly improved due to the advent of targeted therapy and immunotherapy (185). 
However, drug resistance remains to be a challenge for the treatment of cancer. The mechanisms of drug resistance include: i) Heterogeneity of tumor cells; ii) the TME, including hypoxia, abnormal angiogenesis, EMT, tumor metabolic recombination and the immunosuppressive microenvironment; iii) tumor stem cells; iv) mutation of the drug target gene or signaling compensation; v) detoxification mechanism; vi) pharmacological changes, such as drug inactivation, decreased drug absorption, enhanced drug metabolic activity and increased expression of drug efflux transporter; vii) reduction in the sensitivity of apoptosis; and 8) increase in the ability to repair DNA damage (185). Previous studies have confirmed that a high concentration of ROS is one of the characteristics of drug-resistance in cancer cells $(186,187)$. ROS can promote drug resistance in tumors through a variety of mechanisms. As such, ROS can promote the formation of an immunosuppressive microenvironment and mediate resistance to immunotherapy by promoting the phenotypes of MDSCs, DCs and TAMs (106). ROS can also promote EMT, where cells undergoing EMT typically exhibit characteristics of cancer stem cells, with high rates of self-renewal and resistance to drugs and radiation (188). In addition, ROS can regulate the expression of multidrug resistance genes, such as the transmembrane drug efflux protein P-glycoprotein (P-gp), and ATP-dependent substrate transport on both mRNA and protein levels (186). Therefore, blocking ROS has been proposed to overcome resistance to chemotherapy. However, ROS has also been found to promote the sensitivity of tumor cells to drug treatment $(11,12)$. The levels of ROS in tumors are generally higher than those observed in normal cells obtained from the same tissue source (24). Therefore, once the levels of ROS exceed the threshold through continuous accumulation, the cells will undergo apoptosis (35). RT and a number of chemotherapeutic drugs, including cisplatin, 5-fluorouracil and oxaliplatin can kill tumor cells by promoting the excessive accumulation of ROS. However, tumor cells can initiate the mechanism for the inhibition of the excessive accumulation of ROS, to develop drug resistance (189). Wang et al (190) found that inhibition of solute carrier family 7 member 11 using vorinostat, an inhibitor of histone deacetylase, can lead to an increase in ROS in drug-resistant melanoma cells to lethal levels, which lead to apoptosis only in drug-resistant cells. CSCs consist of a subpopulation of tumor cells that is resistant to chemotherapy and are characterized by high invasiveness and metastasis (191). Choi et al (192) previously demonstrated that CSCs can maintain low ROS levels by coupling forkhead box M1-dependent peroxiredoxin 3 expression and fatty acid oxidation-mediated NADPH regeneration, both of which are essential for maintaining the biological characteristics of CSCs. The accumulation of ROS in vivo and in vitro can render CSCs sensitive to RT and chemotherapy $(193,194)$. In addition, the production of ROS, especially mitochondrial-derived ROS, is essential for the induction of apoptosis, autophagy and ICD of tumor cells. Therefore, ROS-based nanotechnology can increase the sensitivity of tumor cells to RT, chemotherapy, targeted therapy and immunotherapy (195-198). The relationship between ROS and drug-resistant tumors is highly complex, where various studies yielded conflicting findings. For example, P-gp was found to be overexpressed in MCF-7 cells after treatment with a low concentration of $\mathrm{H}_{2} \mathrm{O}_{2}$

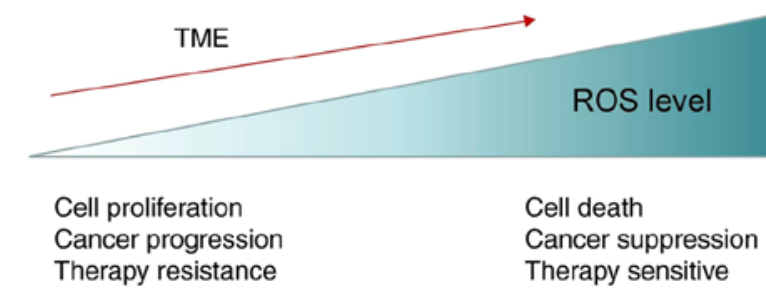

Figure 4. Different levels of ROS exert varied biological effects on tumors Low levels of ROS may play a more tumor-promoting role, whereas lethal levels of ROS have the opposite effect on promoting the death of tumor cells and increasing their sensitivity to treatment. ROS, reactive oxygen species; TME, tumor microenvironment.

(1 M) (199). However, a high concentration of $\mathrm{H}_{2} \mathrm{O}_{2}(10 \mathrm{M})$ downregulated the expression of $\mathrm{P}$-gp in human myelogenous leukemia K562/DOX cells (200). These studies were conducted in different cell lines, such that some conclusions remained contradictory. Therefore, the relationship between ROS and multidrug resistance warrants further comprehensive investigation (Fig. 4).

\section{Conclusions}

If a malignant tumor is known as a 'seed', the TME can be termed as the 'soil' that allows the 'seed' to grow. The TME serves a key role in several steps of tumor development, including local drug resistance, immune escape and distant metastasis $(15,18,19)$. The combination of immune checkpoint inhibitors or cell therapy with microenvironment-targeted therapy is expected to improve the prognosis of patients with cancer in the future (201). Tumor cells are characterized by indefinite proliferative potential, which is frequently accompanied with local tissue hypoxia, abnormal angiogenesis and metabolic reprogramming (202). In addition, persistent endoplasmic reticulum stress appears to be a new feature of tumors, which allows tumor cells to adapt to carcinogenic and environmental challenges to coordinate different immunomodulatory mechanisms and promote tumor progression $(203,204)$. ROS production caused by hypoxia, metabolic reprogramming and endoplasmic reticulum stress altogether serve an important role in the cross-dialogue between the tumor and the surrounding microenvironment. ROS plays a dual role in intracellular signal transduction and cell fate regulation in this process (Fig. 4), the levels of which in cancer cells are largely dependent on the antioxidant defense system (186). Therefore, increasing the levels ROS to accurately break the redox balance is the key prerequisite for the effective treatment of cancer. However, ROS can also promote tumor cell proliferation, vascular proliferation, CAF differentiation, immune escape and drug resistance. It has been suggested that there are different pools of ROS in cancer cells with differing functions (205). ROS derived from NADPH oxidase can promote the proliferation of small intestinal crypt cells, whereas ROS induced by p53-induced glycolysis and apoptosis regulator (TIGAR) deletion can exert the opposite effect (206). NADPH oxidase produces extracellular superoxides, while TIGAR protects against intracellular ROS damage by supporting the pentose phosphate pathway (206). The beneficial or harmful effects of ROS in cells are not necessarily mutually exclusive. 
Further studies on the different tumor cell types, ROS levels and even the level-effect relationship between ROS and tumor cells are required. Collectively, these findings indicate that the combination of ROS-based redox regulators with standard RT and chemotherapy or even immunotherapy may be of great significance in tumor therapy.

\section{Acknowledgements}

Not applicable.

\section{Funding}

Not applicable.

\section{Availability of data and materials}

Not applicable.

\section{Authors' contributions}

YCS conceptualized the design of the present review. WL and XYH performed the literature search wrote the paper. JQB and TTH made several revisions of the text, making crucial contributions to the scientific analysis and discussion of the thesis presented in the review. All authors have read and agreed to the published version of the manuscript.

\section{Ethics approval and consent to participate}

Not applicable.

\section{Patient consent for publication}

Not applicable.

\section{Competing interests}

The authors declare that they have no competing interests.

\section{References}

1. Nosaka Y and Nosaka AY: Generation and detection of reactive oxygen species in photocatalysis. Chem Rev 117: 11302-11336, 2017.

2. Kumari S, Badana AK, G MM GS and Malla RR: Reactive oxygen species: A key constituent in cancer survival. Biomark Insights 13: 1177271918755391, 2018.

3. Valko M,Leibfritz D, Moncol J, Cronin MT, Mazur M and Telser J: Free radicals and antioxidants in normal physiological functions and human disease. Int J Biochem Cell Biol 39: 44-84, 2007.

4. Yang B, Chen Y and Shi J: Reactive oxygen species (ROS)-based nanomedicine. Chem Rev 119: 4881-4985, 2019.

5. Cruces-Sande A, Rodríguez-Pérez AI, Herbello-Hermelo P, Bermejo-Barrera P, Méndez-Álvarez E, Labandeira-García JL and Soto-Otero R: Copper increases brain oxidative stress and enhances the ability of 6-hydroxydopamine to cause dopaminergic degeneration in a rat model of parkinson's disease. Mol Neurobiol 56: 2845-2854, 2019.

6. Gorrini C, Harris IS and Mak TW: Modulation of oxidative stress as an anticancer strategy. Nat Rev Drug Discov 12: 931-947, 2013

7. Chatterjee R and Chatterjee J: ROS and oncogenesis with special reference to EMT and stemness. Eur J Cell Biol 99: 151073, 2020.

8. Okon IS and Zou MH: Mitochondrial ROS and cancer drug resistance: Implications for therapy. Pharmacol Res 100: 170-174, 2015.
9. Birben E, Sahiner UM, Sackesen C, Erzurum S and Kalayci O: Oxidative stress and antioxidant defense. World Allergy Organ J 5: 9-19, 2012.

10. Parekh A, Das S, Parida S, Das CK, Dutta D, Mallick SK, Wu PH, Kumar BNP, Bharti R, Dey G, et al: Multi-nucleated cells use ROS to induce breast cancer chemo-resistance in vitro and in vivo. Oncogene 37: 4546-4561, 2018.

11. Li Z, Guo D, Yin X, Ding S, Shen M, Zhang R, Wang Y and $\mathrm{Xu}$ R: Zinc oxide nanoparticles induce human multiple myeloma cell death via reactive oxygen species and Cyt-C/Apaf-1/Caspase-9/Caspase-3 signaling pathway in vitro. Biomed Pharmacother 122: 109712, 2020.

12. Xia B and Wang J: Effects of adenosine on apoptosis of ovarian cancer a2780 cells via ROS and caspase pathways. Onco Targets Ther 12: 9473-9480, 2019.

13. Hanahan D and Coussens LM: Accessories to the crime: Functions of cells recruited to the tumor microenvironment. Cancer Cell 21: 309-322, 2012.

14. Guo X, Cheng Y, Zhao X, Luo Y, Chen J and Yuan WE: Advances in redox-responsive drug delivery systems of tumor microenvironment. J Nanobiotechnology 16: 74, 2018.

15. Zheng J and Gao P: Toward normalization of the tumor microenvironment for cancer therapy. Integr Cancer Ther 18: $1534735419862352,2019$.

16. Paget S: The distribution of secondary growths in cancer of the breast. 1889. Cancer Metastasis Rev 8: 98-101, 1989.

17. Langley RR and Fidler IJ: The seed and soil hypothesis revisited-the role of tumor-stroma interactions in metastasis to different organs. Int J Cancer 128: 2527-2535, 2011.

18. Akhtar M, Haider A, Rashid S and Al-Nabet ADMH: Paget's 'seed and soil' theory of cancer metastasis: An idea whose time has come. Adv Anat Patho 26: 69-74, 2019.

19. Zhao Y, Li J, Li D, Wang Z, Zhao J, Wu X, Sun Q, Lin PP, Plum P, Damanakis A, et al: Tumor biology and multidisciplinary strategies of oligometastasis in gastrointestinal cancers. Semin Cancer Biol 60: 334-343, 2020.

20. Malla R, Surepalli N, Farran B, Malhotra SV and Nagaraju GP: Reactive oxygen species (ROS): Critical roles in breast tumor microenvironment. Crit Rev Oncol Hematol 160: 103285, 2021.

21. Kuo CL, Chou HY, Chiu YC, Cheng AN, Fan CC, Chang YN, Chen $\mathrm{CH}$, Jiang SS, Chen NJ and Lee AY: Mitochondrial oxidative stress by Lon-PYCR1 maintains an immunosuppressive tumor microenvironment that promotes cancer progression and metastasis. Cancer Lett 474: 138-150, 2020.

22. An J, Hu YG, Cheng K, Li C, Hou XL, Wang GL, Zhang XS, Liu B, Zhao YD and Zhang MZ: ROS-augmented and tumor-microenvironment responsive biodegradable nanoplatform for enhancing chemo-sonodynamic therapy. Biomaterials 234: 119761, 2020.

23. Arfin S, Jha NK, Jha SK, Kesari KK, Ruokolainen J, Roychoudhury S, Rathi B and Kumar D: Oxidative stress in cancer cell metabolism. Antioxidants (Basel) 10: 642, 2021.

24. Mirzaei S, Hushmandi K, Zabolian A, Saleki H, Torabi SMR, Ranjbar A, SeyedSaleh S, Sharifzadeh SO, Khan H, Ashrafizadeh M, et al: Elucidating role of reactive oxygen species (ROS) in cisplatin chemotherapy: A focus on molecular pathways and possible therapeutic strategies. Molecules 26: 2382, 2021.

25. Igney FH and Krammer PH: Death and anti-death: Tumour resistance to apoptosis. Nat Rev Cancer 2: 277-288, 2002.

26. Saxena N, Yadav P and Kumar O: The Fas/Fas ligand apoptotic pathway is involved in abrin-induced apoptosis. Toxicol Sci 135: 103-118, 2013.

27. Jo E, Jang HJ, Yang KE, Jang MS, Huh YH, Yoo HS, Park JS, Jang IS and Park SJ: Cordyceps militaris induces apoptosis in ovarian cancer cells through TNF- $\alpha /$ TNFR1-mediated inhibition of NF-кB phosphorylation. BMC Complement Med Ther 20: 1, 2020.

28. Zhang P, Wang H, Chen Y, Lodhi A, Sun C, Sun F, Yan L, Deng Y and Ma H: DR5 related autophagy can promote apoptosis in gliomas after irradiation. Biochem Biophys Res Commun 522: 910-916, 2020.

29. Bergeron S, Beauchemin M and Bertrand R: Camptothecinand etoposide-induced apoptosis in human leukemia cells is independent of cell death receptor- 3 and -4 aggregation but accelerates tumor necrosis factor-related apoptosis-inducing ligand-mediated cell death. Mol Cancer Ther 3: 1659-1669, 2004.

30. Brenner C, Cadiou H, Vieira HL, Zamzami N, Marzo I, Xie Z, Leber B, Andrews D, Duclohier H, Reed JC and Kroemer G: Bcl-2 and Bax regulate the channel activity of the mitochondrial adenine nucleotide translocator. Oncogene 19: 329-336, 2000. 
31. Sun KX and Xia HW: Pachymic acid inhibits growth and induces cell cycle arrest and apoptosis in gastric cancer SGC-7901 cells Oncol Lett 16: 2517-2524, 2018.

32. Haque M and Islam M: Pleurotus mushroom induces apoptosis by altering the balance of proapoptotic and antiapoptotic genes in breast cancer cells and inhibits tumor sphere formation. Medicina (Kaunas) 55: 716, 2019.

33. Kim JS, Cho IA, Kang KR, Lim H, Kim TH, Yu SK, Kim HJ, Lee SA, Moon SM, Chun HS, et al: Reversine induces caspase-dependent apoptosis of human osteosarcoma cells through extrinsic and intrinsic apoptotic signaling pathways Genes Genomics 41: 657-665, 2019.

34. Kuranaga E: Beyond apoptosis: Caspase regulatory mechanisms and functions in vivo. Genes Cells 17: 83-97, 2012.

35. Moloney JN and Cotter TG: ROS signalling in the biology of cancer. Semin Cell Dev Biol 80: 50-64, 2018

36. Lin S, Li Y, Zamyatnin AA Jr, Werner J and Bazhin AV: Reactive oxygen species and colorectal cancer. J Cell Physiol 233: 5119-5132, 2018

37. Lin B, Chen H, Liang D, Lin W, Qi X, Liu H and Deng X: Acidic $\mathrm{pH}$ and high- $\mathrm{H}_{2} \mathrm{O}_{2}$ dual tumor microenvironment-responsive nanocatalytic graphene oxide for cancer selective therapy and recognition. ACS Appl Mater Interfaces 11: 11157-11166, 2019.

38. Choi EJ and Jeon SM: NRF2-driven redox metabolism takes center stage in cancer metabolism from an outside-in perspective. Arch Pharm Res 43: 321-336, 2020.

39. Um HD: Bcl-2 family proteins as regulators of cancer cell invasion and metastasis: A review focusing on mitochondrial respiration and reactive oxygen species. Oncotarget 7: 5193-5203, 2016.

40. You L, Dong X, Ni B, Fu J, Yang C, Yin X, Leng X and Ni J: Triptolide induces apoptosis through fas death and mitochondrial pathways in HepaRG cell line. Front Pharmacol 9: 813, 2018

41. Zhu Q, Guo Y, Chen S, Fu D, Li Y, Li Z and Ni C: Irinotecan induces autophagy-dependent apoptosis and positively regulates ROS-related JNK- and p38-MAPK pathways in gastric cancer cells. Onco Targets Ther 13: 2807-2817, 2020.

42. Zang YQ, Feng YY, Luo YH, Zhai YQ, Ju XY, Feng YC, Sheng YN, Wang JR, Yu CQ and Jin $\mathrm{CH}$ : Quinalizarin induces ROS-mediated apoptosis via the MAPK, STAT3 and NF-kB signaling pathways in human breast cancer cells. Mol Med Rep 20: 4576-4586, 2019.

43. Hwang KE, Park C, Kwon SJ, Kim YS, Park DS, Lee MK, Kim BR, Park SH, Yoon KH, Jeong ET, et al: Synergistic induction of apoptosis by sulindac and simvastatin in A549 human lung cancer cells via reactive oxygen species-dependent mitochondrial dysfunction. Int J Oncol 43: 262-270, 2013.

44. Zhang T, He WH, Feng LL and Huang HG: Effect of doxorubicin-induced ovarian toxicity on mouse ovarian granulosa cells. Regul Toxicol Pharmacol 86: 1-10, 2017.

45. Liu H, Jiang W, Wang Q, Hang L, Wang Y and Wang Y: ROS-sensitive biomimetic nanocarriers modulate tumor hypoxia for synergistic photodynamic chemotherapy. Biomater Sci 7: 3706-3716, 2019.

46. Lopes TZ, de Moraes FR, Tedesco AC, Arni RK, Rahal P and Calmon MF: Berberine associated photodynamic therapy promotes autophagy and apoptosis via ROS generation in renal carcinoma cells. Biomed Pharmacother 123: 109794, 2020.

47. Mowers EE, Sharifi MN and Macleod KF: Functions of autophagy in the tumor microenvironment and cancer metastasis. FEBS J 285: 1751-1766, 2018.

48. Gao L, Loveless J, Shay C and Teng Y: Targeting ROS-mediated crosstalk between autophagy and apoptosis in cancer. Adv Exp Med Biol 1260: 1-12, 2020

49. Li L, Tan J, Miao Y, Lei P and Zhang Q: ROS and autophagy: Interactions and molecular regulatory mechanisms. Cell Mol Neurobiol 35: 615-621, 2015.

50. Wu Z, Wang H, Fang S and Xu C: Roles of endoplasmic reticulum stress and autophagy on $\mathrm{H} 2 \mathrm{O} 2$-induced oxidative stress injury in HepG2 cells. Mol Med Rep 18: 4163-4174, 2018.

51. Lien JC, Lin MW, Chang SJ, Lai KC, Huang AC, Yu FS and Chung JG: Tetrandrine induces programmed cell death in human oral cancer CAL 27 cells through the reactive oxygen species production and caspase-dependent pathways and associated with beclin-1-induced cell autophagy. Environ Toxicol 32: 329-343, 2017.

52. Kim KY, Park KI, Kim SH, Yu SN, Park SG, Kim YW, Seo YK, Ma JY and Ahn SC: Inhibition of autophagy promotes salinomycin-induced apoptosis via reactive oxygenspecies-mediated $\mathrm{PI} 3 \mathrm{~K} / \mathrm{AKT} / \mathrm{mTOR}$ and ERK/p38 MAPK-dependent signaling in human prostate cancer cells. Int J Mol Sci 18: 1088, 2017.
53. Wei B, Huang Q, Huang $S$, Mai W and Zhong $X$ : Trichosanthin-induced autophagy in gastric cancer cell MKN-45 is dependent on reactive oxygen species (ROS) and NF- $\kappa \mathrm{B} / \mathrm{p} 53$ pathway. J Pharmacol Sci 131: 77-83, 2016.

54. Li L, Chen Y and Gibson SB: Starvation-induced autophagy is regulated by mitochondrial reactive oxygen species leading to AMPK activation. Cell Signa 25: 50-65, 2013.

55. Zhang DW, Shao J, Lin J, Zhang N, Lu BJ, Lin SC, Dong MQ and Han J: RIP3, an energy metabolism regulator that switches TNF-induced cell death from apoptosis to necrosis. Science 325 332-336, 2009

56. Schenk B and Fulda S: Reactive oxygen species regulate Smac mimetic/TNF $\alpha$-induced necroptotic signaling and cell death. Oncogene 34: 5796-5806, 2015.

57. Li Y, Gong P, Kong C and Tian X: Bufalin engages in RIP1-dependent and ROS-dependent programmed necroptosis in breast cancer cells by targeting the RIP1/RIP3/PGAM5 pathway. Anticancer Drugs 30: e0770, 2019.

58. Zhang Y, Su SS, Zhao S, Yang Z, Zhong CQ, Chen X, Cai Q, Yang Z, Huang D, Wu R and Han J: RIP1 autophosphorylation is promoted by mitochondrial ROS and is essential for RIP3 recruitment into necrosome. Nat Commun 8: 14329, 2017.

59. Pawlikowska M, Piotrowski J, Jedrzejewski T, Kozak W, Slominski AT and Brożyna AA: Coriolus versicolor-derived protein-bound polysaccharides trigger the caspase-independent cell death pathway in amelanotic but not melanotic melanoma cells. Phytother Res 34: 173-183, 2020.

60. Yang Z, Wang Y, Zhang Y, He X, Zhong CQ, Ni H, Chen X, Liang Y, Wu J,Zhao S, et al: RIP3 targets pyruvate dehydrogenase complex to increase aerobic respiration in TNF-induced necroptosis. Nat Cell Biol 20: 186-197, 2018.

61. Tu HC, Ren D, Wang GX, Chen DY, Westergard TD, Kim H, Sasagawa S, Hsieh JJ and Cheng EH: The p53-cathepsin axis cooperates with ROS to activate programmed necrotic death upon DNA damage. Proc Natl Acad Sci USA 106: 1093-1098, 2009.

62. Ying Y and Padanilam BJ: Regulation of necrotic cell death: $\mathrm{p} 53$, PARP1 and cyclophilin D-overlapping pathways of regulated necrosis? Cell Mol Life Sci 73: 2309-2324, 2016.

63. Zheng Q and Hou W: Regulation of angiogenesis by microRNAs in cancer. Mol Med Rep 24: 583, 2021.

64. Aggarwal V, Tuli HS, Varol A, Thakral F, Yerer MB, Sak K, Varol M, Jain A, Khan MA and Sethi G: Role of reactive oxygen species in cancer progression: Molecular mechanisms and recent advancements. Biomolecules 9: 735, 2019.

65. Liu B, Cui LS, Zhou B, Zhang LL, Liu ZH and Zhang L: Monocarbonyl curcumin analog A2 potently inhibits angiogenesis by inducing ROS-dependent endothelial cell death. Acta Pharmacol Sin 40: 1412-1423, 2019.

66. Watson EC, Grant ZL and Coultas L: Endothelial cell apoptosis in angiogenesis and vessel regression. Cell Mol Life Sci 74: 4387-4403, 2017

67. Sakamaki K: Regulation of endothelial cell death and its role in angiogenesis and vascular regression. Curr Neurovasc Res 1: 305-315, 2004

68. Miao Y, Cui L, Chen Z and Zhang L: Gene expression profiling of DMU-212-induced apoptosis and anti-angiogenesis in vascular endothelial cells. Pharm Biol 54: 660-666, 2016.

69. Li GH, Lin XL, Zhang H, Li S, He XL, Zhang K, Peng J, Tang YL, Zeng JF, Zhao Y, et al: Ox-Lp(a) transiently induces HUVEC autophagy via an ROS-dependent PAPR-1-LKB1-AMPK-mTOR pathway. Atherosclerosis 243: 223-235, 2015. Corrigendum in: Atherosclerosis 250: 189, 2016.

70. Topalovski M, Hagopian M, Wang M and Brekken RA: Hypoxia and transforming growth factor $\beta$ cooperate to induce fibulin-5 expression in pancreatic cancer. J Biol Chem 291: 22244-22252, 2016.

71. ZeferinoRC,MotaNSRS,Grinevicius VMAS,FilipeKB,SulisPM, Silva FRMB, Filho DW, Pich CT and Pedrosa RC: Targeting ROS overgeneration by N-benzyl-2-nitro-1-imidazole-acetamide as a potential therapeutic reposition approach for cancer therapy. Invest New Drugs 38: 785-799, 2020.

72. Duraipandy N, Dharunya G, Lakra R, Korapatti PS and Syamala Kiran M: Fabrication of plumbagin on silver nanoframework for tunable redox modulation: Implications for therapeutic angiogenesis. J Cell Physiol 234: 13110-13127, 2019.

73. Cao J, Liu X, Yang Y, Wei B, Li Q, Mao G, He Y, Li Y, Zheng L, Zhang $\mathrm{Q}$, et al: Decylubiquinone suppresses breast cancer growth and metastasis by inhibiting angiogenesis via the ROS/p53/ BAI1 signaling pathway. Angiogenesis 23: 325-338, 2020 
74. Nurmik M, Ullmann P, Rodriguez F, Haan S and Letellier E In search of definitions: Cancer-associated fibroblasts and their markers. Int J Cancer 146: 895-905, 2020.

75. Liao Z, Tan ZW, Zhu P and Tan NS: Cancer-associated fibroblasts in tumor microenvironment-Accomplices in tumor malignancy. Cell Immunol 343: 103729, 2019.

76. Pereira BA, Vennin C, Papanicolaou M, Chambers CR, Herrmann D, Morton JP, Cox TR and Timpson P: CAF Subpopulations: A new reservoir of stromal targets in pancreatic cancer. Trends Cancer 5: 724-741, 2019.

77. Kim BG, Sung JS, Jang Y, Cha YJ, Kang S, Han HH, Lee JH and Cho NH: Compression-induced expression of glycolysis genes in CAFs correlates with EMT and angiogenesis gene expression in breast cancer. Commun Biol 2: 313, 2019.

78. Eiro N, González L, Martínez-Ordoñez A, Fernandez-Garcia B González LO, Cid S, Dominguez F, Perez-Fernandez R and Vizoso FJ: Cancer-associated fibroblasts affect breast cancer cell gene expression, invasion and angiogenesis. Cell Oncol (Dordr) 41: 369-378, 2018.

79. Takahashi H, Sakakura K, Kudo T, Toyoda M, Kaira K, Oyama T and Chikamatsu K: Cancer-associated fibroblasts promote an immunosuppressive microenvironment through the induction and accumulation of protumoral macrophages. Oncotarget 8 : 8633-8647, 2017

80. Yan Y, Chen X, Wang X, Zhao Z, Hu W, Zeng S, Wei J, Yang X, Qian L, Zhou S, et al: The effects and the mechanisms of autophagy on the cancer-associated fibroblasts in cancer. J Exp Clin Cancer Res 38: 171, 2019.

81. Zhang X, Schönrogge M, Eichberg J, Wendt EHU, Kumstel S, Stenzel J, Lindner T, Jaster R, Krause B, Vollmar B and Zechner D: Blocking autophagy in cancer-associated fibroblasts supports chemotherapy of pancreatic cancer cells. Front Oncol 8 : $590,2018$.

82. Attieh Y and Vignjevic D: The hallmarks of CAFs in cancer invasion. Eur J Cell Biol 95: 493-502, 2016.

83. Yao Q, Qu X, Yang Q, Wei M and Kong B: CLIC4 mediates TGF-beta1-induced fibroblast-to-myofibroblast transdifferentiation in ovarian cancer. Oncol Rep 22: 541-548, 2009.

84. Sampson N, Brunner E, Weber A, Puhr M, Schäfer G, Szyndralewiez C and Klocker H: Inhibition of Nox4-dependent ROS signaling attenuates prostate fibroblast activation and abrogates stromal-mediated protumorigenic interactions. Int $\mathbf{J}$ Cancer 143: 383-395, 2018.

85. Toullec A, Gerald D, Despouy G, Bourachot B, Cardon M, Lefort S, Richardson M, Rigaill G, Parrini MC, Lucchesi C, et al: Oxidative stress promotes myofibroblast differentiation and tumour spreading. EMBO Mol Med 2: 211-230, 2010.

86. Martinez-Outschoorn UE, Lisanti MP and Sotgia F: Catabolic cancer-associated fibroblasts transfer energy and biomass to anabolic cancer cells, fueling tumor growth. Semin Cancer Biol 25: 47-60, 2014.

87. Lisanti MP, Martinez-Outschoorn UE, Chiavarina B, Pavlides S, Whitaker-Menezes D, Tsirigos A, Witkiewicz A, Lin Z, Balliet R, Howell A and Sotgia F: Understanding the 'lethal' drivers of tumor-stroma co-evolution: Emerging role(s) for hypoxia, oxidative stress and autophagy/mitophagy in the tumor microenvironment. Cancer Biol Ther 10: 537-542, 2010.

88. Martinez-Outschoorn UE, Trimmer C, Lin Z, Whitaker-Menezes D, Chiavarina B, Zhou J, Wang C, Pavlides S, Martinez-Cantarin MP, Capozza F, et al: Autophagy in cancer associated fibroblasts promotes tumor cell survival: Role of hypoxia, HIF1 induction and $\mathrm{NF \kappa B}$ activation in the tumor stromal microenvironment. Cell Cycle 9: 3515-3533, 2010.

89. Bernard M, Yang B, Migneault F, Turgeon J, Dieudé M, Olivier MA, Cardin GB, El-Diwany M, Underwood K, Rodier F and Hébert MJ: Autophagy drives fibroblast senescence through MTORC2 regulation. Autophagy 16: 2004-2016, 2020.

90. Urbano AM: Otto Warburg: The journey towards the seminal discovery of tumor cell bioenergetic reprogramming. Biochim Biophys Acta Mol Basis Dis 1867: 165965, 2021.

91. Zhang D, Wang Y, Shi Z, Liu J, Sun P, Hou X, Zhang J, Zhao S, Zhou BP and Mi J: Metabolic reprogramming of cancer-associated fibroblasts by IDH $3 \alpha$ downregulation. Cell Rep 10: 1335-1348, 2015.

92. Martinez-Outschoorn UE, Goldberg A, Lin Z, Ko YH Flomenberg N, Wang C, Pavlides S, Pestell RG, Howell A, Sotgia $\mathrm{F}$ and Lisanti MP: Anti-estrogen resistance in breast cancer is induced by the tumor microenvironment and can be overcome by inhibiting mitochondrial function in epithelial cancer cells. Cancer Biol Ther 12: 924-938, 2011.
93. Feng $X, X u$ W, Li Z, Song W, Ding $J$ and Chen $X$ : Immunomodulatory nanosystems. Adv Sci (Weinh) 6: 1900101, 2019.

94. Hamieh M, Dobrin A, Cabriolu A, van der Stegen SJC, Giavridis T, Mansilla-Soto J, Eyquem J, Zhao Z, Whitlock BM, Miele MM, et al: CAR T cell trogocytosis and cooperative killing regulate tumour antigen escape. Nature 568: 112-116, 2019.

95. Strickler JH, Hanks BA and Khasraw M: Tumor mutational burden as a predictor of immunotherapy response: Is more always better? Clin Cancer Res 27: 1236-1241, 2021.

96. Carreau N and Pavlick A: Revolutionizing treatment of advanced melanoma with immunotherapy. Surg Oncol: Jan 12 2019 (Epub ahead of print).

97. Boyero L, Sánchez-Gastaldo A, Alonso M, Noguera-Uclés JF, Molina-Pinelo S and Bernabé-Caro R: Primary and acquired resistance to immunotherapy in lung cancer: Unveiling the mechanisms underlying of immune checkpoint blockade therapy. Cancers (Basel) 12: 3729, 2020.

98. Anichini A, Perotti VE, Sgambelluri F and Mortarini R: Immune escape mechanisms in non small cell lung cancer. Cancers (Basel) 12: 3605, 2020.

99. Marshall LA, Marubayashi S, Jorapur A, Jacobson S,Zibinsky M, Robles O, Hu DX, Jackson JJ, Pookot D, Sanchez J, et al: Tumors establish resistance to immunotherapy by regulating Treg recruitment via CCR4. J Immunother Cancer 8: e000764, 2020.

100. Mima K, Kosumi K, Baba Y, Hamada T, Baba H and Ogino S: The microbiome, genetics, and gastrointestinal neoplasms: The evolving field of molecular pathological epidemiology to analyze the tumor-immune-microbiome interaction. Hum Genet 140: 725-746, 2021.

101. Ali AMR, Tsai JW, Leung CH, Lin H, Ravi V, Conley AP, Lazar AJ, Wang WL and Nathenson MJ: The immune microenvironment of uterine adenosarcomas. Clin Sarcoma Res 10: 5, 2020 .

102. Kosmaczewska A, Ciszak L, Potoczek S and Frydecka I: The significance of Treg cells in defective tumor immunity. Arch Immunol Ther Exp (Warsz) 56: 181-191, 2008.

103. Lindau D, Gielen P, Kroesen M, Wesseling P and Adema GJ: The immunosuppressive tumour network: Myeloid-derived suppressor cells, regulatory $\mathrm{T}$ cells and natural killer $\mathrm{T}$ cells. Immunology 138: 105-115, 2013.

104. Augustin RC, Delgoffe GM and Najjar YG: Characteristics of the tumor microenvironment that influence immune cell functions: Hypoxia, oxidative stress, metabolic alterations. Cancers (Basel) 12: 3802, 2020

105. Lötscher J and Balmer ML: Sensing between reactions-how the metabolic microenvironment shapes immunity. Clin Exp Immunol 197: 161-169, 2019.

106. Kotsafti A, Scarpa M, Castagliuolo I and Scarpa M: Reactive oxygen species and antitumor immunity-from surveillance to evasion. Cancers (Basel) 12: 1748, 2020.

107. Yin Y, Jiang X, Sun L, Li H, Su C, Zhang Y, Xu G, Li X, Zhao C, Chen Y, Xu H and Zhang K: Continuous inertial cavitation evokes massive ROS for reinforcing sonodynamic therapy and immunogenic cell death against breast carcinoma. Nano Today 36: 101009, 2021.

108. Yang J, Ma S, Xu R, Wei Y, Zhang J, Zuo T, Wang Z, Deng H, Yang N and Shen Q: Smart biomimetic metal organic frameworks based on ROS-ferroptosis-glycolysis regulation for enhanced tumor chemo-immunotherapy. J Control Release 334: 21-33, 2021

109. Nakamura Y, Zhenjie Z, Oya K, Tanaka R, Ishitsuka Y, Okiyama N, Watanabe R and Fujisawa Y: Poor lymphocyte infiltration to primary tumors in acral lentiginous melanoma and mucosal melanoma compared to cutaneous melanoma. Front Oncol 10: 524700, 2020

110. Murphy MP and Siegel RM: Mitochondrial ROS fire up T cell activation. Immunity 38: 201-202, 2013.

111. Kaminski MM, Sauer SW, Klemke CD, Süss D, Okun JG, Krammer PH and Gülow K: Mitochondrial reactive oxygen species control T cell activation by regulating IL- 2 and IL-4 expression: Mechanism of ciprofloxacin-mediated immunosuppression. J Immunol 184: 4827-4841, 2010.

112. Li Y, Liang R, Zhang X, Wang J, Shan C, Liu S, Li L and Zhang S: Copper chaperone for superoxide dismutase promotes breast cancer cell proliferation and migration ROS-Mediated MAPK/ERK signaling. Front Pharmacol 10: 356, 2019.

113. Ball JA, Vlisidou I, Blunt MD, Wood W and Ward SG: Hydrogen peroxide triggers a dual signaling axis to selectively suppress activated human T lymphocyte migration. J Immunol 198: 3679-3689, 2017. 
114. Wang L, Kuang Z, Zhang D, Gao Y, Ying M and Wang T: Reactive oxygen species in immune cells: A new antitumor target. Biomed Pharmacother 133: 110978, 2021.

115. Belikov AV, Schraven B and Simeoni L: T cells and reactive oxygen species. J Biomed Sci 22: 85, 2015

116. Scharping NE, Rivadeneira DB, Menk AV, Vignali PDA, Ford BR, Rittenhouse NL, Peralta R, Wang Y, Wang Y, DePeaux K, et al: Mitochondrial stress induced by continuous stimulation under hypoxia rapidly drives $\mathrm{T}$ cell exhaustion. Nat Immunol 22: 205-215, 2021

117. Franco F, Jaccard A, Romero P, Yu YR and Ho PC: Metabolic and epigenetic regulation of T-cell exhaustion. Nat Metab 2 : 1001-1012, 2020.

118. Salas-Benito D, Conde E, Tamayo-Uria I, Mancheño U, Elizalde E, Garcia-Ros D, Aramendia JM, Muruzabal JC, Alcaide J, Guillen-Grima F, et al: The mutational load and a T-cell inflamed tumour phenotype identify ovarian cancer patients rendering tumour-reactive T cells from PD-1+tumour-infiltrating lymphocytes. Br J Cancer 124: 1138-1149, 2021.

119. Kumar A, Chamoto K, Chowdhury PS and Honjo T: Tumors attenuating the mitochondrial activity in $\mathrm{T}$ cells escape from PD-1 blockade therapy. Elife 9: e52330, 2020.

120. Chamoto K, Chowdhury PS, Kumar A, Sonomura K, Matsuda F, Fagarasan S and Honjo T: Mitochondrial activation chemicals synergize with surface receptor PD-1 blockade for T cell-dependent antitumor activity. Proc Natl Acad Sci USA 114: E761-E770, 2017.

121. Xia Y, Jia C, Xue Q, Jiang J, Xie Y, Wang R, Ran Z, Xu F, Zhang Y and Ye T: Antipsychotic drug trifluoperazine suppresses colorectal cancer by inducing G0/G1 arrest and apoptosis. Front Pharmacol 10: 1029, 2019.

122. Bailly C: Regulation of PD-L1 expression on cancer cells with ROS-modulating drugs. Life Sci 246: 117403, 2020.

123. Liu K, Du S, Gao P and Zheng J: Verteporfin suppresses the proliferation, epithelial-mesenchymal transition and stemness of head and neck squamous carcinoma cells via inhibiting YAP1. J Cancer 10: 4196-4207, 2019

124. Marangoni F, Zhakyp A, Corsini M, Geels SN, Carrizosa E, Thelen M, Mani V, Prüßmann JN, Warner RD, Ozga AJ, et al: Expansion of tumor-associated Treg cells upon disruption of a CTLA-4-dependent feedback loop. Cell: Jun 21, 2021 (Epub ahead of print).

125. Ni D, Tang T, Lu Y, Xu K, Shao Y, Saaoud F, Saredy J, Liu L, Drummer C 4th, Sun Y, et al: Canonical secretomes, innate immune caspase-1-, 4/11-gasdermin D non-canonical secretomes and exosomes may contribute to maintain treg-ness for treg immunosuppression, tissue repair and modulate anti-tumor immunity via ROS pathways. Front Immunol 12: 678201, 2021.

126. Hang S, Paik D, Yao L, Kim E, Trinath J, Lu J, Ha S, Nelson BN Kelly SP, Wu L, et al: Bile acid metabolites control T(H)17 and T(reg) cell differentiation. Nature 576: 143-148, 2019.

127. Kunisada Y, Eikawa S, Tomonobu N, Domae S, Uehara T, Hori S, Furusawa Y, Hase K, Sasaki A and Udono H: Attenuation of CD4 $+\mathrm{CD} 25+$ regulatory $\mathrm{T}$ cells in the tumor microenvironment by metformin, a type 2 diabetes drug. EBioMedicine 25: 154-164, 2017

128. Yu X, Lao Y, Teng XL, Li S, Zhou Y, Wang F, Guo X, Deng S, Chang Y, Wu X, et al: SENP3 maintains the stability and function of regulatory $\mathrm{T}$ cells via $\mathrm{BACH} 2$ deSUMOylation. Nat Commun 9: 3157, 2018

129. Maj T, Wang W, Crespo J, Zhang H, Wang W, Wei S, Zhao L, Vatan L, Shao I,Szeliga W, et al: Oxidative stress controls regulatory $\mathrm{T}$ cell apoptosis and suppressor activity and PD-L1-blockade resistance in tumor. Nat Immunol 18: 1332-1341, 2017.

130. Betten A, Dahlgren C, Mellqvist UH, Hermodsson S and Hellstrand K: Oxygen radical-induced natural killer cel dysfunction: Role of myeloperoxidase and regulation by serotonin. J Leukoc Biol 75: 1111-1115, 2004.

131. Zheng X, Qian Y, Fu B, Jiao D, Jiang Y, Chen P, Shen Y, Zhang H, Sun R, Tian $\mathrm{Z}$ and Wei H: Mitochondrial fragmentation limits NK cell-based tumor immunosurveillance. Nat Immunol 20 1656-1667, 2019.

132. Mimura K, Kua LF, Shimasaki N, Shiraishi K, Nakajima S, Siang LK, Shabbir A, So J, Yong WP and Kono K: Upregulation of thioredoxin-1 in activated human NK cells confers increased tolerance to oxidative stress. Cancer Immunol Immunother 66 : 605-613, 2017.

133. Aydin E, Johansson J, Nazir FH, Hellstrand K and Martner A: Role of NOX2-derived reactive oxygen species in NK cell-mediated control of murine melanoma metastasis. Cancer Immunol Res 5: 804-811, 2017.
134. Aurelius J, Martner A, Riise RE, Romero AI, Palmqvist L, Brune M, Hellstrand K and Thorén FB: Chronic myeloid leukemic cells trigger poly(ADP-ribose) polymerase-dependent inactivation and cell death in lymphocytes. J Leukoc Biol 93 $155-160,2013$

135. Gu FF, Zhang K, Ma LL, Liu YY, Li C, Hu Y, Yang QF, Liang JY, Zeng YL, Wang Y and Liu L: The superior ability of human BDCA3 + (CD141 +) dendritic cells (DCs) to cross-present antigens derived from necrotic lung cancer cells. Front Immunol 11: 1267, 2020

136. Paardekooper LM, Vos W and van den Bogaart G: Oxygen in the tumor microenvironment: Effects on dendritic cell function. Oncotarget 10: 883-896, 2019.

137. Giovanelli P, Sandoval TA and Cubillos-Ruiz JR: Dendritic cell metabolism and function in tumors. Trends Immunol 40 699-718, 2019

138. Chougnet CA, Thacker RI, Shehata HM, Hennies CM, Lehn MA, Lages CS and Janssen EM: Loss of phagocytic and antigen cross-presenting capacity in aging dendritic cells is associated with mitochondrial dysfunction. J Immunol 195 2624-2632, 2015.

139. Mao D, Hu F, Yi Z, Kenry, Xu S, Yan S, Luo Z, Wu W, Wang Z, Kong D, et al: AIEgen-coupled upconversion nanoparticles eradicate solid tumors through dual-mode ROS activation. Sci Adv 6: eabb2712, 2020

140. Wang C,Li P,Liu L, Pan H, Li H, Cai L and Ma Y: Self-adjuvanted nanovaccine for cancer immunotherapy: Role of lysosomal rupture-induced ROS in MHC class I antigen presentation. Biomaterials 79: 88-100, 2016.

141. Oberkampf M, Guillerey C, Mouriès J, Rosenbaum P, Fayolle C, Bobard A, Savina A, Ogier-Denis E, Enninga J, Amigorena $\mathrm{S}$, et al: Mitochondrial reactive oxygen species regulate the induction of CD8 $\mathrm{T}$ cells by plasmacytoid dendritic cells. Nature Commun 9: 2241, 2018

142. DeNardo D and Ruffell B: Macrophages as regulators of tumour immunity and immunotherapy. Nat Rev Immunol 19: 369-382, 2019

143. Allavena P, Anfray C, Ummarino A and Andón FT: Therapeutic manipulation of tumor-associated macrophages: Facts and hopes from a clinical and translational perspective. Clin Cancer Res 27: 3291-3297, 2021.

144. Zhang J, Li H, Wu Q, Chen Y, Deng Y, Yang Z, Zhang L and Liu B: Tumoral NOX4 recruits M2 tumor-associated macrophages via ROS/PI3K signaling-dependent various cytokine production to promote NSCLC growth. Redox Biol 22: 101116, 2019

145. Li L, Sun F, Han L, Liu X, Xiao Y, Gregory AD, Shapiro SD, Xiao G and Qu Z: PDLIM2 repression by ROS in alveolar macrophages promotes lung tumorigenesis. JCI Insight 6: e144394, 2021.

146. Lin X, Zheng W, Liu J, Zhang Y, Qin H, Wu H, Xue B, Lu Y and Shen P: Oxidative stress in malignant melanoma enhances tumor necrosis factor- $\alpha$ secretion of tumor-associated macrophages that promote cancer cell invasion. Antioxid Redox Signal 19: $1337-1355,2013$

147. Griess B, Mir S, Datta K and Teoh-Fitzgerald M: Scavenging reactive oxygen species selectively inhibits M2 macrophage polarization and their pro-tumorigenic function in part, via Stat3 suppression. Free Radic Biol Med 147: 48-60, 2020.

148. Ruan J, Ouyang M, Zhang W, Luo Y and Zhou D: The effect of PD-1 expression on tumor-associated macrophage in $\mathrm{T}$ cell lymphoma. Clin Transl Oncol 23: 1134-1141, 2021.

149. Wei Y, Huang CX, Xiao X, Chen DP, Shan H, He H and Kuang DM: B cell heterogeneity, plasticity, and functional diversity in cancer microenvironments. Oncogene: Jun 29, 2021 (Epub ahead of print)

150. Helmink BA, Reddy SM, Gao J, Zhang S, Basar R, Thakur R Yizhak K, Sade-Feldman M, Blando J, Han G, et al: B cells and tertiary lymphoid structures promote immunotherapy response. Nature 577: 549-555, 2020

151. Cabrita R, Lauss M, Sanna A, Donia M, Skaarup Larsen M, Mitra S, Johansson I, Phung B, Harbst K, et al: Tertiary lymphoid structures improve immunotherapy and survival in melanoma. Nature 577: 561-565, 2020.

152. Petitprez F, de Reyniès A, Keung EZ, Chen TW, Sun CM, Calderaro J, Jeng YM, Hsiao LP, Lacroix L, Bougoüin A, et al: $B$ cells are associated with survival and immunotherapy response in sarcoma. Nature 577: 556-560, 2020.

153. Jang JW, Thuy PX, Lee JW and Moon EY: CXCR4 promotes $\mathrm{B}$ cell viability by the cooperation of nuclear factor (erythroid-derived 2)-like 2 and hypoxia-inducible factor- $1 \alpha$ under hypoxic conditions. Cell Death Dis 12: 330, 2021. 
154.Feng YY, Tang M, Suzuki M, Gunasekara C, Anbe Y, Hiraoka Y, Liu J, Grasberger H, Ohkita M, Matsumura Y, et al: Essential role of NADPH oxidase-dependent production of reactive oxygen species in maintenance of sustained $\mathrm{B}$ Cell receptor signaling and b cell proliferation. J Immunol 202: 2546-2557, 2019

155. Jang KJ, Mano H, Aoki K, Hayashi T, Muto A, Nambu Y, Takahashi K, Itoh K, Taketani S, Nutt SL, et al: Mitochondrial function provides instructive signals for activation-induced B-cell fates. Nat Commun 6: 6750, 2015.

156. Onnis A, Cianfanelli V, Cassioli C, Samardzic D, Pelicci PG, Cecconi $\mathrm{F}$ and Baldari CT: The pro-oxidant adaptor p66SHC promotes B cell mitophagy by disrupting mitochondrial integrity and recruiting LC3-II. Autophagy 14: 2117-2138, 2018.

157. Onnis A, Cassioli C, Finetti F and Baldari CT: Regulation of selective B cell autophagy by the pro-oxidant adaptor p66SHC. Front Cell Dev Biol 8: 193, 2020.

158. Yin K, Xia X, Rui K, Wang T and Wang S: Myeloid-derived suppressor cells: A new and pivotal player in colorectal cancer progression. Front Oncol 10: 610104, 2020.

159. Ohl K and Tenbrock K: Reactive oxygen species as regulators of MDSC-mediated immune suppression. Front Immunol 9: 2499, 2018.

160. Kusmartsev S and Gabrilovich DI: Inhibition of myeloid cell differentiation in cancer: The role of reactive oxygen species. J Leukoc Biol 74: 186-196, 2003.

161. Park MJ, Lee SH, Kim EK, Lee EJ, Baek JA, Park SH, Kwok SK and Cho ML: Interleukin-10 produced by myeloid-derived suppressor cells is critical for the induction of Tregs and attenuation of rheumatoid inflammation in mice. Sci Rep 8 $3753,2018$.

162. Fortin C, Yang Y and Huang X: Monocytic myeloid-derived suppressor cells regulate $\mathrm{T}$-cell responses against vaccinia virus. Eur J Immunol 47: 1022-1031, 2017.

163. Zhu J, Huang X and Yang Y: Myeloid-derived suppressor cells regulate natural killer cell response to adenovirus-mediated gene transfer. J Virol 86: 13689-13696, 2012.

164. Dong G, Yang Y, Li X, Yao X, Zhu Y, Zhang H, Wang H, Ma Q, Zhang J, Shi H, et al: Granulocytic myeloid-derived suppressor cells contribute to IFN-I signaling activation of B cells and disease progression through the lncRNA NEAT1-BAFF axis in systemic lupus erythematosus. Biochim Biophys Acta Mol Basis Dis 1866: 165554, 2020.

165. Jaufmann J, Lelis FJN, Teschner AC, Fromm K, Rieber N, Hartl D and Beer-Hammer S: Human monocytic myeloid-derived suppressor cells impair B-cell phenotype and function in vitro. Eur J Immunol 50: 33-47, 2020.

166. Lelis FJN, Jaufmann J, Singh A, Fromm K, Teschner AC Pöschel S, Schäfer I, Beer-Hammer S, Rieber N and Hartl D Myeloid-derived suppressor cells modulate B-cell responses. Immunol Lett 188: 108-115, 2017.

167. Satoh H, Moriguchi T, Taguchi K, Takai J, Maher JM, Suzuki T, Winnard PT Jr, Raman V, Ebina M, Nukiwa T and Yamamoto M: Nrf2-deficiency creates a responsive microenvironment for metastasis to the lung. Carcinogenesis 31: 1833-1843, 2010.

168. Saleh R and Elkord E: Acquired resistance to cancer immunotherapy: Role of tumor-mediated immunosuppression. Semin Cancer Biol 65: 13-27, 2020.

169. Hernández ÁP, Juanes-Velasco P, Landeira-Viñuela A Bareke H, Montalvillo E, Góngora R and Fuentes M: Restoring the immunity in the tumor microenvironment: Insights into immunogenic cell death in onco-therapies. Cancers (Basel) 13: $2821,2021$.

170. Galluzzi L, Buqué A, Kepp O, Zitvogel L and Kroemer G: Immunogenic cell death in cancer and infectious disease. Nat Rev Immunol 17: 97-111, 2017.

171. Li Z, Zhu L, Sun H, Shen Y, Hu D, Wu W, Wang Y, Qian C and Sun M: Fluorine assembly nanocluster breaks the shackles of immunosuppression to turn the cold tumor hot. Proc Natl Acad Sci USA 117: 32962-32969, 2020.

172. Deng H, Yang W, Zhou Z, Tian R, Lin L, Ma Y, Song J and Chen X: Targeted scavenging of extracellular ROS relieves suppressive immunogenic cell death. Nat Commun 11: 4951, 2020

173. Garg AD, Dudek AM, Ferreira GB, Verfaillie T, Vandenabeele P, Krysko DV, Mathieu C and Agostinis P: ROS-induced autophagy in cancer cells assists in evasion from determinants of immunogenic cell death. Autophagy 9: 1292-1307, 2013.

174. Buono R and Longo VD: Starvation, stress resistance, and cancer. Trends Endocrinol Metab 29: 271-280, 2018.
175. Li XX, Wang ZJ, Zheng Y, Guan YF, Yang PB, Chen X, Peng C, He JP, Ai YL, Wu SF, et al: Nuclear receptor Nur77 facilitates melanoma cell survival under metabolic stress by protecting fatty acid oxidation. Mol Cell 69: 480-492 e7, 2018.

176. Sullivan LB and Chandel NS: Mitochondrial reactive oxygen species and cancer. Cancer Metab 2: 17, 2014

177. Wu Z, Zuo M, Zeng L, Cui K, Liu B, Yan C, Chen L, Dong J, Shangguan F, Hu W, et al: OMA1 reprograms metabolism under hypoxia to promote colorectal cancer development. EMBO Rep 22: e50827, 2020.

178. Wang YP, Zhou W, Wang J, Huang X, Zuo Y, Wang TS, Gao X, Xu YY, Zou SW, Liu YB, et al: Arginine Methylation of MDH1 by CARM1 inhibits glutamine metabolism and suppresses pancreatic cancer. Mol Cell 64: 673-687, 2016.

179. Panieri E, Telkoparan-Akillilar P, Suzen S and Saso L: The NRF2/KEAP1 axis in the regulation of tumor metabolism: Mechanisms and therapeutic perspectives. Biomolecules 10: $791,2020$.

180. Shao S, Qin T, Qian W, Yue Y, Xiao Y, Li X, Zhang D, Wang Z, Ma Q and Lei J: Positive feedback in Cav-1-ROS signalling in PSCs mediates metabolic coupling between PSCs and tumour cells. J Cell Mol Med 24: 9397-9408, 2020.

181. Ilkhani K, Bastami M, Delgir S, Safi A, Talebian S and Alivand MR: The engaged role of tumor microenvironment in cancer metabolism: Focusing on cancer-associated fibroblast and exosome mediators. Anticancer Agents Med Chem 21: 254-266, 2021

182. Zhai Y, Chai L and Chen J: The relationship between the expressions of tumor associated fibroblasts Cav- 1 and MCT4 and the prognosis of papillary carcinoma of breast. Pak J Pharm Sci 30 (Suppl 1): S263-S372, 2017.

183. Ngwa VM, Edwards DN, Philip $M$ and Chen J: Microenvironmental metabolism regulates antitumor immunity. Cancer Res 79: 4003-4008, 2019.

184. Song M, Sandoval TA, Chae CS, Chopra S, Tan C, Rutkowski MR, Raundhal M, Chaurio RA, Payne KK, Konrad C, et al: IRE1 $\alpha$-XBP1 controls T cell function in ovarian cancer by regulating mitochondrial activity. Nature 562: 423-428, 2018.

185. Gottesman MM, Lavi O, Hall MD and Gillet JP: Toward a better understanding of the complexity of cancer drug resistance. Annu Rev Pharmacol Toxicol 56: 85-102, 2016.

186. Cui Q, Wang JQ, Assaraf YG, Ren L, Gupta P, Wei L, Ashby CR Jr, Yang DH and Chen ZS: Modulating ROS to overcome multidrug resistance in cancer. Drug Resist Updat 41: 1-25, 2018

187. Jadhao M, Tsai EM, Yang HC, Chen YF, Liang SS, Wang TN, Teng YN, Huang HW, Wang LF and Chiu CC: The long-term DEHP exposure confers multidrug resistance of triple-negative breast cancer cells through ABC transporters and intracellular ROS. Antioxidants (Basel) 10: 949, 2021.

188. Lee SY, Jeong EK, Ju MK, Jeon HM, Kim MY, Kim CH, Park HG, Han SI and Kang HS: Induction of metastasis, cancer stem cell phenotype, and oncogenic metabolism in cancer cells by ionizing radiation. Mol Cancer 16: 10, 2017.

189. Ge W, Zhao K, Wang X, Li H, Yu M, He M, Xue X, Zhu Y, Zhang $\mathrm{C}$, Cheng Y, et al: iASPP is an antioxidative factor and drives cancer growth and drug resistance by competing with Nrf2 for Keap1 Binding. Cancer Cell 32: 561-573.e6, 2017

190. Wang L, Leite de Oliveira R, Huijberts S, Bosdriesz E, Pencheva N, Brunen D, Bosma A, Song JY, Zevenhoven J, Los-de Vries GT, et al: An acquired vulnerability of drug-resistant melanoma with therapeutic potential. Cell 173: 1413-1425. e14, 2018.

191. Menéndez ST, Gallego B, Murillo D, Rodríguez A and Rodríguez R: Cancer stem cells as a source of drug resistance in bone sarcomas. J Clin Med 10: 2621, 2021.

192. Choi HJ, Jhe YL, Kim J, Lim JY, Lee JE, Shin MK and Cheong JH: FoxM1-dependent and fatty acid ox idation-mediated ROS modulation is a cell-intrinsic drug resistance mechanism in cancer stem-like cells. Redox Biol 36: 101589, 2020.

193. Banerjee S, Mukherjee S, Bhattacharya A, Basak U, Chakraborty S, Paul S, Khan P, Jana K, Hazra TK and Das T: Pyridoxine enhances chemo-responsiveness of breast cancer stem cells via redox reconditioning. Free Radic Biol Med 152: $152-165,2020$

194. Li D, Fu Z, Chen R, Zhao X, Zhou Y, Zeng B, Yu M, Zhou Q, Lin $\mathrm{Q}, \mathrm{Gao} \mathrm{W}$, et al: Inhibition of glutamine metabolism counteracts pancreatic cancer stem cell features and sensitizes cells to radiotherapy. Oncotarget 6: 31151-31163, 2015. 
195. Tsai TL, Lai YH, Hw Chen H and Su WC: Overcoming radiation resistance by iron-platinum metal alloy nanoparticles in human copper transport 1-overexpressing cancer cells via mitochondrial disturbance. Int J Nanomedicine 16: 2071-2085, 2021.

196. Li Q, Zhang J, Li J, Ye H, Li M, Hou W, Li H and Wang Z: Glutathione-activated NO-/ROS-generation nanoparticles to modulate the tumor hypoxic microenvironment for enhancing the effect of HIFU-combined chemotherapy. ACS Appl Mater Interfaces 13: 26808-26823, 2021

197. Chen W, Yu D, Sun SY and Li F: Nanoparticles for co-delivery of osimertinib and selumetinib to overcome osimertinib-acquired resistance in non-small cell lung cancer. Acta Biomater 29 258-268, 2021.

198. Banstola A, Poudel K, Pathak S, Shrestha P, Kim JO, Jeong JH and Yook S: Hypoxia-mediated ROS amplification triggers mitochondria-mediated apoptotic cell death via PD-L1/ROS-responsive, dual-targeted, drug-laden thioketal nanoparticles. ACS Appl Mater Interfaces 13: 22955-22969, 2021.

199. Cen J, Zhang L, Liu F, Zhang F and Ji BS: Long-term alteration of reactive oxygen species led to multidrug resistance in MCF-7 cells. Oxid Med Cell Longev 2016: 7053451, 2016.

200. Wang J, Liu L, Cen J and Ji B: BME, a novel compound of anthraquinone, down regulated P-glycoprotein expression in doxorubicin-resistant human myelogenous leukemia (K562/DOX) cells via generation of reactive oxygen species. Chem Biol Interact 239: 139-145, 2015.
201. Murciano-Goroff YR, Warner AB and Wolchok JD: The future of cancer immunotherapy: Microenvironment-targeting combinations. Cell Res 30: 507-519, 2020.

202. Reina-Campos M, Moscat J and Diaz-Meco M: Metabolism shapes the tumor microenvironment. Curr Opin Cell Biol 48: 47-53, 2017.

203. Chen $X$ and Cubillos-Ruiz J: Endoplasmic reticulum stress signals in the tumour and its microenvironment. Nat Rev Cancer 21: 71-88, 2021.

204. Andrews AM, Tennant MD and Thaxton JE: Stress relief for cancer immunotherapy: Implications for the ER stress response in tumor immunity. Cancer Immunol Immunother 70: 1165-1175, 2020

205. Harris IS and DeNicola GM: The Complex Interplay between Antioxidants and ROS in Cancer. Trends Cell Biol 30: 440-451, 2020.

206. Cheung EC, Lee P, Ceteci F, Nixon C, Blyth K, Sansom OJ and Vousden KH: Opposing effects of TIGAR- and RAC1-derived ROS on Wnt-driven proliferation in the mouse intestine. Genes Dev 30: 52-63, 2016.

This work is licensed under a Creative Commons Attribution-NonCommercial-NoDerivatives 4.0 International (CC BY-NC-ND 4.0) License. 